\title{
FINANCIAL CRISIS AND SLOW RECOVERY WITH BAYESIAN LEARNING AGENTS
}

\author{
Ryo Horii \\ Yoshiyasu Ono
}

March 2020

The Institute of Social and Economic Research

Osaka University

6-1 Mihogaoka, Ibaraki, Osaka 567-0047, Japan 


\title{
Financial Crisis and Slow Recovery
}

\section{with Bayesian Learning Agents*}

\author{
Ryo Horii ${ }^{\dagger}$ and Yoshiyasu Ono
}

March 31, 2020

\begin{abstract}
In a simple continuous-time model where the learning process affects the willingness to hold liquidity, we provide an intuitive explanation of business cycle asymmetry and post-crisis slow recovery. When observing a liquidity shock, individuals rationally increase their subjective probability of re-encountering it. It leads to an upward jump in liquidity preference and a discrete fall in consumption. Conversely, as a period without shocks continues, they gradually decrease the subjective probability, reduce liquidity preference, and increase consumption. The recovery process is particularly slow after many shocks are observed within a short period because people do not easily change their pessimistic view.
\end{abstract}

Keywords and phrases: Bayesian Updating, Liquidity Preference, Markov Switching, Asymmetric Cycles, Persistence

JEL Classifications: E32, E41, D83.

*The authors are grateful to V.V. Chari, Kazuo Mino, Akihisa Shibata, and seminar participants at the University of Tokyo, the Tokyo Institute of Technology, the Delhi School of Economics, and the Summer Workshop on Macroeconomics held at the University of Auckland for their helpful comments and suggestions. This research is supported by JSPS KAKENHI Grant 15H01948, 15H05728, 15 H03329 and 16K13353, and partly funded by the Behavioral Economics Research Center at ISER, Osaka University. An earlier version of this paper was circulated as "Learning, Liquidity Preference, and Business Cycle."

${ }^{\dagger}$ Correspondence: ISER, Osaka University, 6-1 Mihogaoka, Ibaraki-shi, Osaka, 567-0047, JAPAN; Email: horii@econ.jpn.org

${ }^{\ddagger}$ ISER, Osaka University; E-mail ono@iser.osaka-u.ac.jp 


\section{Introduction}

This paper considers a situation where economic agents hold money to prepare for a possible aggregate liquidity shock, such as the global financial crisis of 2008 and the recent Coronavirus shock of 2020. In normal times, the benefit of holding liquidity is limited because agents can settle transactions by relying on short-term credits, such as credit cards. However, once a financial crisis occurs, and obtaining credits becomes difficult, holding money stock yields an explicit benefit. Bank runs are another example of such liquidity shocks. Usually, people need not hold much cash since they can easily withdraw deposits. When a bank run occurs, cash has advantages over deposits. However, since people cannot foresee when a crisis occurs, they have some incentive to hold money all the time.

The expected benefit of holding money depends on the subjective probability of encountering liquidity shock. The probability is not necessarily constant over time. ${ }^{1}$ For example, during the global financial crisis of 2007-2008, many banks failed in succession, and the shortage of liquidity occurred across the globe, one after another. By observing the situation, firms and individuals must have learned that the economy is more likely to be hit by another shock in the near future, and therefore have incentives to hold more liquidity in preparation. Similar patterns happened during the collapse of bubbles in Japan in the 1990s, European debt crisis of 2010-2012, and also in the recent crisis caused by Coronavirus (COVID-19) pandemic of 2020.

To formalize this learning process and examine the resulting dynamics of the economy, we introduce Markov-switching states in a money-in-the-utility model. In the model, agents receive utility from holding money only when the liquidity shock occurs. There are two unobservable states, stable and unstable, between which the economy goes back and forth according to a Markov process. The liquidity shock follows a Poisson process in each state with different arrival rates. By observing whether or not the shock occurs at each

\footnotetext{
${ }^{1}$ Atolia et al. (2018) suggest that liquidity shocks, or tight credit conditions, are more likely to be observed during economic downturns (see Figure 1 in their paper). Their paper also quantitatively shows that the financial frictions (i.e., liquidity shocks) are only active occasionally and that they are a significant source of macroeconomic volatility over the business cycle.
} 
point in time, agents rationally update the subjective probability using Bayes' law and revise the time paths of money holding. In this setting, when agents observe the shock, they strengthen the belief that they are in the unstable state, increase their subjective probability for re-encountering the shock, and raise liquidity preference. Conversely, if the shock does not occur for a while, they gradually increase the belief of being in a safer state, reduce the shock probability, and lower liquidity preference.

To map the evolution of liquidity preference to macroeconomic dynamics, we combine the learning process with a minimal macroeconomic setup with incomplete nominal price adjustments. The higher the subjective probability of meeting the shock, the more willing the agents become to hold money, sacrificing their consumption. The resulting movements in aggregate consumption further intensify fluctuations in liquidity preference. When people lower consumption due to high liquidity preference, the shortage in aggregate demand will push down the inflation rate. Lower inflation reduces the cost of holding money, further intensifying the liquidity preference. Furthermore, since people anticipate that employment will decline after a liquidity shock, they want to increase savings by holding more money if they believe the shock is likely. Both of these mechanisms strengthen the connection among the belief of agents, their liquidity preference, and consumption.

This paper contributes to the literature of business cycles in two aspects. First, it provides a natural explanation for the observed asymmetry of the business cycles. Empirical works found that Macroeconomic variables tend to move quicker in contraction than in expansion. ${ }^{2}$ However, in typical linearized business cycle models, the economy fluctuates symmetrically around the steady state. In a continuous-time model, our model shows that the movements of the output and employment are asymmetric since, while sudden discrete shocks reveal bad news, the good news is known only from the length of the period without

\footnotetext{
${ }^{2}$ The observation that the business cycles are asymmetric dates back to Keynes (1936). Neftci (1984), Sichel (1993), and Acemoglu and Scott (1997) are among the empirical works that identified the asymmetric movement of output. Later studies focused on the relative degree of asymmetry among the key macroeconomic variables. See, for example, Sichel (1993), Hansen and Prescott (2005), McKay and Reis (2008), and Ferraro (2018).
} 
shocks. The realized pattern of output is asymmetric even when the underlying Markovswitching model is symmetric. The asymmetry occurs because of the way the information is brought to the agents.

The model also provides an intuitive mechanism for the high persistence of output loss from the sizeable financial crisis. ${ }^{3}$ We show that the persistence is higher after the economy is hit by multiple shocks in a short time, while the recovery is relatively quick if a shock is an isolated event. This difference occurs because each realized shock only partially reveals information about the true state. As long as the liquidity shock occurs sparsely in time, people view the shock as a mere accident. Although consumption decreases temporarily, it quickly recovers as the subsequent observation of no shock confirms this optimistic view. However, when the shock occurs many times for a short while, people are convinced that they are in the less stable state. In this case, the recovery process takes a long time, even after the shock ceases. The recovery speed of consumption is initially slow because their pessimistic belief is so strong that it is not easily overturned by the gradually revealed information from the absence of shocks. The recovery process gradually accelerates as the belief gets weaker and more sensitive to new information, and eventually slows down again when they are quite sure that they are in the safer state. ${ }^{4}$

\subsection{Related Studies}

There have been various attempts to explain fluctuations of macroeconomic variables by combining unobservable regime changes and Bayesian updating agents. When the signal is

\footnotetext{
${ }^{3}$ Cerra and Saxena (2008) presented robust evidence that the substantial output loss from financial is highly persistent. Reinhart and Reinhart (2010) found that economic growth is notably slower in the decade following a macroeconomic disruption and provided evidence of several "double dips." Ikeda and Kurozumi (2019) documented the slow recovery after the financial crisis of 1997.

${ }^{4}$ Those results contrast with the previous studies of information cycles by Caplin and Leahy (1993) and Zeira (1994), where a shock, once it occurs, immediately reveals the real state. Even when several shocks come in a bunch, only the first one conveys relevant information. Thus, the number of shocks that agents observe does not affect their behavior. Boldrin and Levine (2001) also consider a related model, but they rule out the possibility that the shock continually occurs.
} 
noisy, agents slowly change their beliefs, making the effect of a regime change a more gradual one than in the case where the state is perfectly observable. Andolfatto and Gomme (2003) and Sill and Wrase (1999), for example, demonstrate that monetary policy has long-lasting effects when it periodically switches between low and high monetary growth in an unobservable way. Other papers examine how agents react to unobservable changes in investment opportunities. Chalkley and Lee (1998) show that recovery from a recession is protracted when risk aversion of agents prevents them from acting promptly on receiving good news. Potter (2000), Veldkamp (2005), and Nieuwerburgh and Veldkamp (2006) explain slow recovery generated by an endogenous flow of information. If agents have a pessimistic belief, their activities are low, generating less public information, and therefore good news is only slowly revealed. This paper proposes an alternative mechanism, where recovery is slow not because the information is scarce in recession, but because people's strong beliefs dwarf the significance of new, favorable information.

Lorenzoni (2009) and Boz et al. (2011) examine related problems, where agents receive the signal on the TFP, but cannot distinguish the transitory and permanent components. Alpanda (2019) extends those studies and incorporates the Markov switching between high and low TFP growth regimes. In these studies, persistent adverse productivity shocks are the ultimate cause of the period of low growth. We complement this literature by considering a mechanism where the economy stagnates for an extended period, even when the production capacity is unaffected.

Specifically, we consider a situation where the decline in output is caused by the shortage of aggregate demand, which is a result of people's strong preference for money, particularly in turbulent times. In this respect, our setting is related to Caballero and Farhi (2018), who develop a framework where excessive demand for safe assets causes stagnation. However, to deliver the macroeconomic implications from the learning process as clearly as possible, we keep our model minimal by assuming a reduced-form relationship between the output gap and the inflation rate, based on a simplified version of Ono (2001), Ono and Ishida (2014), and Illing et al. (2018). These models employ a non-stochastic money-inutility function, where the marginal benefit of holding money has a strictly positive lower 
bound. They have shown that, depending on the parameters for the liquidity preference, the economy can be in persistent stagnation, where output and consumption never recover by themselves. In contrast, this paper examines the possibility that the economy recovers, albeit slowly, if the absence of the shocks gradually lowers liquidity preference through the learning process.

The remainder of the paper is organized as follows. Section 2 presents a model of Bayesian learning in which a representative household faces an aggregate liquidity shock. In Section 3, we examine the effect of fluctuations in belief on the optimal behavior of the household and derive the existence, uniqueness, and other properties of the stationary dynamics. Section 4 shows the pattern of movements of aggregate variables and examines the speed of the recovery process. The role of the learning process in generating an asymmetric pattern is discussed in Section 5. Section 6 summarizes and concludes. Mathematical proof and numerical procedures are provided in the appendices.

\section{Learning Process}

This section sets up a continuous-time model of Bayesian learning in which a representative household faces an aggregate liquidity shock that occurs at random discrete points in time. ${ }^{5}$ We consider a situation in which the arrival rate of the shock changes over time, although it is unobservable to the household. In that setting, this section establishes the following results. (i) When a shock occurs, the household discretely strengthens its belief that the current state of the economy is unstable. (ii) During the period without the shock, the household gradually (or continuously) weakens that belief. (iii) Once the household holds a strong belief that they are in the unstable state, however, the belief can change only slowly, at least for some time. Those results are utilized in later sections to investigate the

\footnotetext{
${ }^{5}$ We use a continuous-time model in order to highlight the difference between the change in belief when bad news arrives and when there is no such news. This strategy is similar to Driffill and Miller (1993) and Zeira (1999). In their models, however, the unobservable state is time-invariant, and the uncertainty eventually vanishes.
} 
pattern of fluctuations in the household's liquidity preference and consumption.

Let us describe the precise settings of the model. There are two underlying states with different probabilities of the shock, called states $\mathrm{H}$ and $\mathrm{L}$. In state $i \in\{H, L\}$, the shock occurs with probability $\theta^{i}$ per unit of time, where $\theta^{H}>\theta^{L}>0$. The household cannot directly observe the current state but knows that the state evolves according to a Markov process: state $\mathrm{H}$ changes to state $\mathrm{L}$ with Poisson probability $p^{H}$ per unit of time whereas state $\mathrm{L}$ changes to state $\mathrm{H}$ with probability $p^{L}$. We assume that the shock occurs much more frequently in state $\mathrm{H}$ than in state $\mathrm{L}$ and that the state change is a rare event when compared to the shock in state H. Formally,

Assumption $1 \theta^{H}-\theta^{L}>p^{H}+p^{L}$.

By observing whether the shock occurs or not the household continuously revises its subjective shock probability in a Bayesian manner. Let $\theta_{t} \in\left\{\theta^{H}, \theta^{L}\right\}$ denote the true shock probability at time $t$, which is unknown to the household. Using information available up to time $t$, it forms a belief that current $\theta_{t}$ is $\theta^{H}$ with probability $\lambda_{t}^{H}$ and $\theta^{L}$ with probability $\lambda_{t}^{L}$. Obviously,

$$
\lambda_{t}^{L}+\lambda_{t}^{H}=1 \text { for all } t
$$

In order to find how the household updates $\lambda_{t}^{i}$ from $t$ to $t+\Delta t,{ }^{6}$ we first obtain the subjective probability that the shock does not occur between $t$ and $t+\Delta t$ for given $\lambda_{t}^{i}$. It is denoted by $\operatorname{Prob}_{t}\left[S_{(t, t+\Delta t]}=\emptyset\right]$, where $\operatorname{Prob}_{t}[\cdot]$ is a probability operator based on information available at $t, S_{(a, b]}$ is the set of dates on which the shock actually occurs during $(a, b]$, and $\emptyset$ the empty set. Since the underlying state is either H or L at time $t+\Delta t$, this probability is divided into two components, $\operatorname{Prob}_{t}\left[S_{(t, t+\Delta t]}=\emptyset \cap \theta_{t+\Delta t}=\theta^{H}\right]$ and $\operatorname{Prob}_{t}\left[S_{(t, t+\Delta t]}=\emptyset \cap \theta_{t+\Delta t}=\theta^{L}\right]$.

Each of the two components is further divided into two probabilities. The former is the sum of the probability that 'the state is $\mathrm{H}$ at time $t$ and neither the state change nor the shock occurs during the interval' and the probability that 'the present state is L and

\footnotetext{
${ }^{6}$ Time interval $\Delta t$ is taken to be so short that the probability that the liquidity shock and a state change coexist in the interval is negligible.
} 
the state changes to $\mathrm{H}$ during the interval.' It is ${ }^{7}$

$$
\operatorname{Prob}_{t}\left[S_{(t, t+\Delta t]}=\emptyset \cap \theta_{t+\Delta t}=\theta^{H}\right]=\left(1-\left(\theta^{H}+p^{H}\right) \Delta t\right) \lambda_{t}^{H}+\left(p^{L} \Delta t\right) \lambda_{t}^{L}
$$

Similarly, the latter is

$$
\operatorname{Prob}_{t}\left[S_{(t, t+\Delta t]}=\emptyset \cap \theta_{t+\Delta t}=\theta^{L}\right]=\left(1-\left(\theta^{L}+p^{L}\right) \Delta t\right) \lambda_{t}^{L}+\left(p^{H} \Delta t\right) \lambda_{t}^{H}
$$

Summing up (2) and (3) yields

$$
\operatorname{Prob}_{t}\left[S_{(t, t+\Delta t]}=\emptyset\right]=1-\theta_{t}^{e} \Delta t
$$

where $\theta_{t}^{e}$ represents the expected (or subjective) probability of the shock per unit of time at time $t$,

$$
\theta_{t}^{e} \equiv \theta^{H} \lambda_{t}^{H}+\theta^{L} \lambda_{t}^{L}
$$

Let us consider how the representative household updates its belief if it eventually finds that the shock did not occur during $(t, t+\Delta t]$. In this case the information that $S_{(t, t+\Delta t]}=\emptyset$ is added to its knowledge. Thus, using Bayes' law we find updated subjective probability $\lambda_{t+\Delta t}^{i}$ to be

$$
\begin{aligned}
\lambda_{t+\Delta t}^{i} & \equiv \operatorname{Prob}_{t+\Delta t}\left[\theta_{t+\Delta t}=\theta^{i}\right]=\operatorname{Prob}_{t}\left[\theta_{t+\Delta t}=\theta^{i} \mid S_{(t, t+\Delta t]}=\emptyset\right] \\
& =\frac{\operatorname{Prob}_{t}\left[S_{(t, t+\Delta t]}=\emptyset \cap \theta_{t+\Delta t}=\theta^{i}\right]}{\operatorname{Prob}_{t}\left[S_{(t, t+\Delta t}=\emptyset\right]} .
\end{aligned}
$$

Since the numerator is given by (2) or (3) and the denominator by (4), $\lambda_{t+\Delta t}^{H}$ equals ${ }^{8}$

$$
\lambda_{t+\Delta t}^{H}=\frac{\left(1-\left(\theta^{H}+p^{H}\right) \Delta t\right) \lambda_{t}^{H}+\left(p^{L} \Delta t\right) \lambda_{t}^{L}}{1-\theta_{t}^{e} \Delta t} .
$$

From this equation we derive the time derivative of $\lambda_{t}^{H}$ as

$$
\dot{\lambda}_{t}^{H}=\lim _{\Delta t \rightarrow 0} \frac{\lambda_{t+\Delta t}^{H}-\lambda_{t}^{H}}{\Delta t}=\left(\theta_{t}^{e}-\theta^{H}-p^{H}\right) \lambda_{t}^{H}+p^{L} \lambda_{t}^{L} .
$$

Next, consider the case where a shock occurs during $(t, t+\Delta t]$. Since

$$
\operatorname{Prob}_{t}\left[S_{(t, t+\Delta t]} \neq \emptyset \cap \theta_{t+\Delta t}=\theta^{i}\right]=\theta^{i} \lambda_{t}^{i} \Delta t \quad \text { for } \quad i \in\{L, H\}
$$

\footnotetext{
${ }^{7}$ Throughout the paper we ignore the second-order term of $\Delta t$ and higher because $\Delta t \rightarrow 0$.

${ }^{8} \lambda_{t+\Delta t}^{L}$ is analogously obtained. From (1) it equals $1-\lambda_{t+\Delta t}^{H}$.
} 
the probability that the shock occurs is

$$
\operatorname{Prob}_{t}\left[S_{(t, t+\Delta t]} \neq \emptyset\right]=\left(\theta^{H} \lambda_{t}^{H}+\theta^{L} \lambda_{t}^{L}\right) \Delta t=\theta_{t}^{e} \Delta t
$$

which is consistent with (4). From Bayes' law dividing (7) by (8) gives the updated subjective probability that $\theta_{t+\Delta t}=\theta^{i}$ under the condition that the shock occurs during $(t, t+\Delta t]$. It is

$$
\lambda_{t}^{i}=\lim _{t^{\prime} \rightarrow t-} \frac{\theta^{i} \lambda_{t^{\prime}}^{i}}{\theta_{t^{\prime}}^{e}} \equiv \frac{\theta^{i} \lambda_{t-}^{i}}{\theta_{t-}^{e}}
$$

where subscript $t$ - represents the state just before $t .{ }^{9}$ Finally, we obtain the dynamics of subjective probability $\theta_{t}^{e}$. From (1) and (5),

$$
\lambda_{t}^{H}=\frac{\theta_{t}^{e}-\theta^{L}}{\theta^{H}-\theta^{L}}, \quad \lambda_{t}^{L}=\frac{\theta^{H}-\theta_{t}^{e}}{\theta^{H}-\theta^{L}} .
$$

Substituting (6) and (10) into the time derivative of (5) yields the time derivative of $\theta_{t}^{e}$ in the case where the shock does not occur at time $t$,

$$
\dot{\theta}_{t}^{e}=\left(\theta_{t}^{e}-\theta^{L}-p^{L}\right)\left(\theta_{t}^{e}-\theta^{H}-p^{H}\right)-p^{L} p^{H} \equiv g\left(\theta_{t}^{e}\right) \quad \text { for } t \notin S_{(0, \infty)} .
$$

Under Assumption 1, this function has an 'U'-shape as illustrated in Figure 1. The figure shows that

$$
\begin{aligned}
g(\theta) & \lesseqgtr 0 \Longleftrightarrow \theta \gtreqless \theta^{*} \text { for any } \theta \in\left[\theta^{L}, \theta^{H}\right], \text { where } \\
\theta^{*} & \equiv \frac{\theta^{L}+\theta^{H}+p^{L}+p^{H}-\sqrt{\left(\theta^{H}+p^{H}-\theta^{L}-p^{L}\right)^{2}+4 p^{L} p^{H}}}{2} \in\left(\theta^{L}, \theta^{H}\right) .
\end{aligned}
$$

Similarly, by substituting (9) and (10) into (5) we obtain the value of $\theta_{t}^{e}$ as a function of $\theta_{t-}^{e}$ in the case where a shock does occur at time $t$.

$$
\theta_{t}^{e}=\theta^{L}+\theta^{H}-\frac{\theta^{L} \theta^{H}}{\theta_{t-}^{e}} \equiv h\left(\theta_{t-}^{e}\right) \quad \text { for } t \in S_{(0, \infty)} .
$$

As shown in Figure 2, $h(\theta)$ satisfies

$$
h\left(\theta^{H}\right)=\theta^{H} \text {, and } \theta^{e}<h\left(\theta^{e}\right)<\theta^{H} \text { for all } \theta^{e} \in\left(\theta^{L}, \theta^{H}\right) .
$$




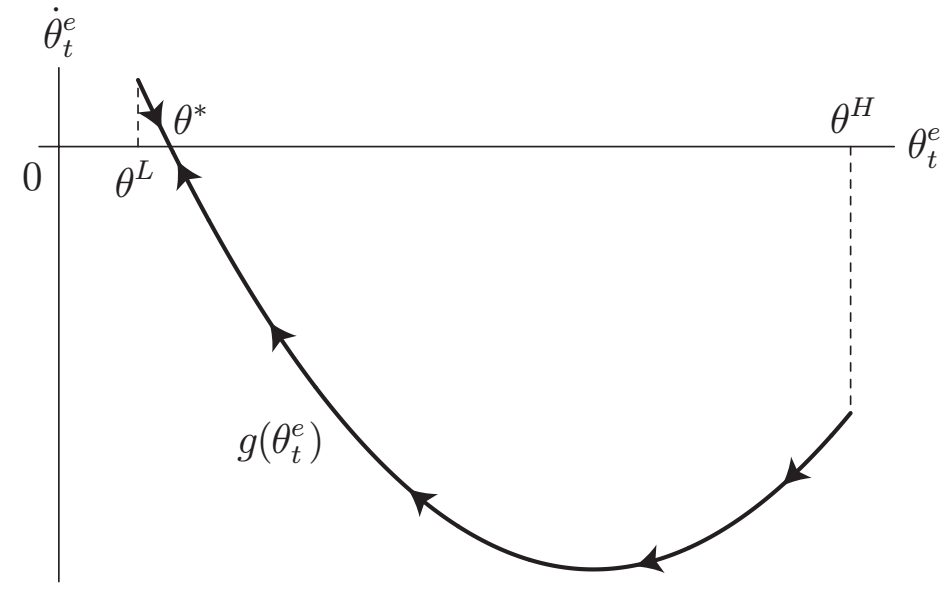

Figure 1: Movement of belief during the period without a shock.

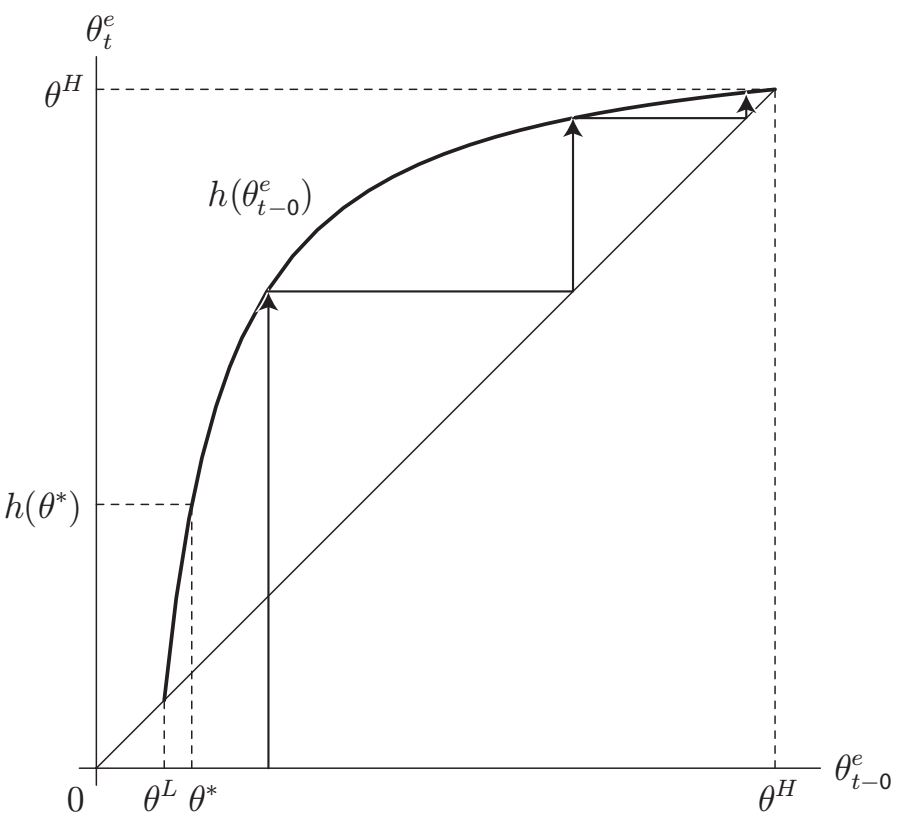

Figure 2: Movement of belief when the shock is observed. 
Equations (11) and (13) respectively describe the dynamics of $\theta_{t}^{e}$ without and with the shock. They jointly show that $\theta_{t}^{e}$ fluctuates within interval $\left(\theta^{*}, \theta^{H}\right]$. A liquidity shock is a rare event, and therefore causes a discrete change in people's expectations about the present state once it occurs. As function $h\left(\theta^{e}\right)$ is located above the 45-degree line in Figure 2 , the more often people observe the shock, the more strongly they believe that they are in state $\mathrm{H}$, and hence $\theta_{t}^{e}$ becomes closer to $\theta^{H}$.

Conversely, in the absence of the shock people gradually become more and more optimistic and confident that the economy is in state L. Thus, their subjective probability of the shock gradually declines, converging to $\theta^{*} .{ }^{10}$ However, the U-shape of function $g\left(\theta_{t}^{e}\right)$ implies that the speed of adjusting belief is slow when $\theta_{t}^{e}$ is near $\theta^{H}$. Note that $\theta_{t}^{e} \approx \theta^{H}$ is equivalent to $\lambda_{t}^{H} \approx 1$ from (10), which means that the precision of the prior belief is quite high (i.e., people are quite sure that the current state is $\mathrm{H}$ ). In that case, any additional information has only a small impact on the posterior belief.

\section{Liquidity Preference and Consumption Behavior}

In this section, we investigate how evolutions in the representative household's beliefs affect their liquidity preference and consumption behavior. We introduce a simple model in which liquidity holding generates utility only when the shock occurs. Since the household cannot anticipate the timing of the shock precisely, they always hold liquidity to prepare for the shock. In this setting, we derive the stationary dynamics in which the household optimally chooses money holding and consumption as a function of their belief on the probability of shock, $\theta_{t}^{e}$.

\footnotetext{
${ }^{9}$ Mathematically, $\theta_{t-}$ is the limit of $\theta_{\tau}$ as $\tau$ approaches $t$ from the left. $\theta_{t-}$ is different from $\theta_{t}$ when belief of the household changes discretely at time $t$. Similar notations are used, for example, in a textbook by Dockner et al. (2000, Chapter 8).

${ }^{10} \theta_{t}^{e}$ never becomes lower than $\theta^{*}\left(>\theta^{L}\right)$ since people take into account the possibility that state $\mathrm{L}$ might have changed to state $\mathrm{H}$ even though the shock does not occur.
} 
In their optimization, the household weighs the cost of holding real money against its benefit. The cost is the sum of the inflation rate and the real interest rate, and the benefit is the expected marginal utility from real money holding. Focusing on each element in this trade-off, this section proceeds in several steps. In the first subsection, we present a minimal setup in which the consumption behavior of the household affects the inflation rate. In the second subsection, we describe the preference of the household as a variant of the money-in-the-utility model and explain how the belief of the household affects the expected benefit from real money holding. The third subsection examines the household's intertemporal optimization under uncertainty. We derive a modified version of the KeynesRamsey rule, which gives the relation between the real interest rate and the growth rate of consumption. The fourth subsection describes the optimality condition for the choice between consumption and money holdings. Combining the results from the previous four subsections, the final subsection derives a difference-differential equation that characterizes the stationary dynamics and establishes its essential properties.

\subsection{Production Side}

Since our focus is on the behavior of the household, we employ a minimal setting for the production side of the economy, where aggregate consumption affects the inflation rate.

The economy is inhabited by the representative households with measure one. Each household lives infinitely and supplies labor to the representative firm. The firm produces homogeneous final goods from labor on a one-to-one basis. The goods market is fully competitive, and the nominal price $P_{t}$ coincides with the nominal marginal cost of production, i.e., the nominal wage level $W_{t}$. There is no investment in our model, and therefore all the produced goods are used for consumption, $c_{t}$. This means that total labor demand $\ell_{t}$ is the same as consumption $c_{t}$.

At each point in time, the household supplies labor elastically. However, if the level of employment is higher than the natural level, which is normalized to one, there is upward pressure on the nominal wage level. Conversely, if the employment is less than one, there is a downward force. For simplicity, instead of explicitly introducing the adjustment cost 
of nominal wages, we assume a reduced-form relationship between employment $\ell_{t}$ and the speed of nominal wage increase $\dot{W}_{t} / W_{t}$ :

$$
\dot{W}_{t} / W_{t}=f\left(\ell_{t}-1\right), \quad f^{\prime}(\cdot) \geq 0
$$

Intuitively, the nominal wage level rises slower (or falls faster) when there is less demand for employment. ${ }^{11}$ From $P_{t}=W_{t}$ and $c_{t}=\ell_{t}$, (14) implies that the inflation rate is determined as a function of aggregate consumption $c_{t}$ :

$$
\pi_{t} \equiv \dot{P}_{t} / P_{t}=f\left(c_{t}-1\right)
$$

Equation (15) can be interpreted as a Phillips curve: a reduced-form relationship between the output gap $c_{t}-1$ and the inflation rate. ${ }^{12}$ In this interpretation, potential output of this economy is normalized to one.

\subsection{Preference of the Household}

We consider a stochastic version of the money-in-the-utility model that incorporates the random liquidity shock. The representative household gains utility from consumption, $c_{t}$. In addition, when the shock occurs, they gain utility in proportion to their real money balances $m_{t}$. Their expected utility $E U_{t}$ is therefore given by

$$
E U_{t}=E_{t}\left[\int_{t}^{\infty} u\left(c_{\tau}\right) e^{-\rho(\tau-t)} d \tau+\sum_{\tau \in S_{(t, \infty)}} \beta m_{\tau} e^{-\rho(\tau-t)}\right]
$$

where constant $\rho$ is their subjective discount rate. Function $u(\cdot)$ represents the instantaneous felicity from consumption, which satisfies the Inada conditions. Constant $\beta$ specifies

\footnotetext{
${ }^{11}$ Our specification is related to Schmitt-Grohé and Uribe (2017), where the maximal rate of nominal wage decline is an increasing function of the unemployment rate. For simplicity, this paper assumes that the relationship holds when the nominal wage moves either direction. In a separate study, we considered the case where there is no upward friction in the nominal wage adjustments, and confirmed that the two main results in this paper (business cycle asymmetry and slow recovery) are retained.

${ }^{12}$ Equation (15) is essentially the same as the Phillips curve in Eggertsson et al. (2019, equation 26) when the output gap is negative.
} 
the marginal benefit from holding real money balances, and therefore $\beta m_{\tau} e^{-\rho(\tau-t)}$ gives the discounted utility from money if a liquidity shock is encountered at date $\tau$. It is summed over $\tau \in S_{(t, \infty)}$, where $S_{(t, \infty)}$ represents the discrete set of dates on which the shock occurs. ${ }^{13}$

Since there is no capital in this economy, money is the only asset that is in positive net supply. The household also has access to the complete set of contingent claims for future goods. However, since all households are identical, money is the only asset that they hold after all arbitrage opportunities are exploited. There is no tax or transfers, and the only source of income for the household is labor. Since the real wage is always unity, their labor income is simply given by employment $\ell_{t}$. With these settings, the flow budget equation can be written as

$$
\dot{m}_{t}=\ell_{t}-\pi_{t} m_{t}-c_{t}
$$

Given the evolution of the subjective shock probability derived in Section 2, the representative household chooses the time paths of consumption and money holding to maximize the expected utility (16) subject to (17).

Objective function (16) depends only on $c_{t}, m_{t}$, and the expected pattern of the shock. From the perspective of economic agents in the model, the last one is fully described by $\theta_{t}^{e}$, since $\theta_{t}^{e}$ is a sufficient statistic for the current and future values of unobservable $\theta_{t}$. Note that, although the budget constraint (17) depends on $\ell_{t}$ and $\pi_{t}$, they are both determined by $c_{t}$ on the realized path: $\ell_{t}=c_{t}$ and $\pi_{t}=f\left(c_{t}-1\right)$ from (15). Therefore, the household's problem can be defined by $c_{t}, m_{t}$, and $\theta_{t}^{e}$. Then, given the recursive structure of the model, the movement of $c_{t}$ on the path of stationary dynamics must completely be expressed as a function of $m_{t}$ and $\theta_{t}^{e} \cdot{ }^{14}$ Furthermore, since objective function (16) and constraint (17)

\footnotetext{
${ }^{13}$ This setting is obviously a simplifying approximation. In reality, a financial crisis does not instantly terminate but continues for a few days so that a household receives, say, utility flow $\tilde{\beta} m_{\tau^{\prime}} e^{-\rho\left(\tau^{\prime}-t\right)}$ throughout $\tau^{\prime} \in[\tau, \tau+T]$. Since each period of financial crisis is typically short, we approximate the total utility received from money holding during one occurrence of the shock by $\beta m_{\tau} e^{-\rho(\tau-t)}$, where $\beta \equiv \tilde{\beta} T$.

${ }^{14}$ This strategy for finding stationary dynamics is analogous to that of Lucas (1978), who analyzes the determination of equilibrium price behavior under an exogenous production shock that follows a Markov
} 
are both linear in $m_{t}$, the optimal choice of $c_{t}$ should be independent of the level of $m_{t} \cdot{ }^{15}$ These consideration reveals that, on the stationary path, $c_{t}$ should be a function only of $\theta_{t}^{e}$

$$
c_{t}=C\left(\theta_{t}^{e}\right) \text { for all } t
$$

Since $\theta_{t}^{e}$ fluctuates within interval $\left(\theta^{*}, \theta^{H}\right]$, as shown in Section 2 , we only need to characterize the shape of function $C\left(\theta_{t}^{e}\right)$ in this interval. In the following it is assumed that $\theta_{t}^{e} \in\left(\theta^{*}, \theta^{H}\right]$ unless otherwise noted.

\subsection{Intertemporal Optimization}

Under complete financial markets, the representative household sells and buys contingent claims to future goods to maximize its lifetime utility. This subsection shows that, even though those contingent claims are in zero net supply, their equilibrium prices are uniquely determined once function $C(\cdot)$ is given. We later use this information to find the opportunity cost of holding real money.

Let $1-\mu\left(\theta_{t}^{e}\right) \Delta t$ denote the price of the claim to a unit of good at $t+\Delta t$ measured in terms of goods at $t$ under the condition that the shock does not occur between $t$ and $t+\Delta t .{ }^{16}$ Note that it is a function of $\theta_{t}^{e}$ because the value of the claim depends on the probability with which the contingent event occurs. ${ }^{17}$ If the shock does not occur during the interval, consumption increases from $C\left(\theta_{t}^{e}\right)$ to $C\left(\theta_{t}^{e}+g\left(\theta_{t}^{e}\right) \Delta t\right)$ since $\theta_{t}^{e}$ changes by

process.

${ }^{15}$ The linearity of the utility function with respect to $m_{t}$ is assumed primarily for showing how the fluctuation in liquidity preference affects the consumption path of the utility-maximizing household in the simplest setting. When the marginal utility of holding real money balances is variable, we actually find that the dynamics of $c_{t}$ depends on both $\theta_{t}^{e}$ and $m_{t}$. We do the analysis for such a general case in a separate paper.

${ }^{16}$ We utilize a method analogous to Ikefuji and Horii (2012, Appendix 8) in solving the continuous-time optimization with the possibility of jumps. They considered the household problem under the risk of being hit by natural disasters.

${ }^{17}$ In addition, $\theta_{t}^{e}$ affects consumption and therefore the marginal utility of consumption. 
the amount of $g\left(\theta_{t}^{e}\right) \Delta t$, as shown by (11). Since the probability that the shock does not occur during this interval is $1-\theta_{t}^{e} \Delta t$, as given by (4), the first-order condition between the present and future consumption under the condition that the shock does not occur is

$$
\left(1-\mu\left(\theta_{t}^{e}\right) \Delta t\right) u^{\prime}\left(C\left(\theta_{t}^{e}\right)\right)=\left(1-\theta_{t}^{e} \Delta t\right) u^{\prime}\left(C\left(\theta_{t}^{e}+g\left(\theta_{t}^{e}\right) \Delta t\right)\right) e^{-\rho \Delta t} .
$$

From this equation in which $\Delta t \rightarrow 0$ we derive

$$
\mu\left(\theta_{t}^{e}\right)=\rho+\theta_{t}^{e}+\frac{C^{\prime}\left(\theta_{t}^{e}\right)}{C\left(\theta_{t}^{e}\right)} \gamma\left(C\left(\theta_{t}^{e}\right)\right) g\left(\theta_{t}^{e}\right) \text { for all } \theta_{t}^{e},
$$

where $\gamma(c) \equiv-u^{\prime \prime}(c) c / u^{\prime}(c)$ represents the degree of risk aversion.

Analogously, let $\nu\left(\theta_{t}^{e}\right) \Delta t$ denote the price of the contingent claim to a unit of good at $t+\Delta t$ under the condition that the shock does occur between $t$ and $t+\Delta t$. When the shock occurs, consumption jumps from $C\left(\theta_{t}^{e}\right)$ to $C\left(h\left(\theta_{t}^{e}\right)\right)$, as seen from (13). Since the shock probability is $\theta_{t}^{e} \Delta t$, as shown by (8), the first-order condition between the present and the future consumption in this case is

$$
\nu\left(\theta_{t}^{e}\right) \Delta t \cdot u^{\prime}\left(C\left(\theta_{t}^{e}\right)\right)=\theta_{t}^{e} \Delta t \cdot u^{\prime}\left(C\left(h\left(\theta_{t}^{e}\right)\right)\right) e^{-\rho \Delta t} .
$$

By making $\Delta t \rightarrow 0$ in this equation we find

$$
\nu\left(\theta_{t}^{e}\right)=\frac{\theta_{t}^{e} u^{\prime}\left(C\left(h\left(\theta_{t}^{e}\right)\right)\right)}{u^{\prime}\left(C\left(\theta_{t}^{e}\right)\right)} \quad \text { for all } \theta_{t}^{e} .
$$

Next, let us derive the rate of return on a risk-free asset, such as a riskless bond. By denoting by $r_{t}$ the real interest rate of a risk-free asset, the price of a risk-free claim to the future good at $t+\Delta t$ can be written as $e^{-r_{t} \Delta t}$. Since the claim is equivalent to the asset of the synthesis of the claim contingent on the absence of the shock whose price is $1-\mu\left(\theta_{t}^{e}\right) \Delta t$ and that conditional on its presence whose price is $\nu\left(\theta_{t}^{e}\right) \Delta t$, the no-arbitrage condition requires

$$
e^{-r_{t} \Delta t}=1-\mu\left(\theta_{t}^{e}\right) \Delta t+\nu\left(\theta_{t}^{e}\right) \Delta t
$$

As $\Delta t \rightarrow 0$, it reduces to

$$
r_{t}=\mu\left(\theta_{t}^{e}\right)-\nu\left(\theta_{t}^{e}\right) \text { for all } t
$$

Substituting (19) and (20) into (21) yields:

$$
C^{\prime}\left(\theta_{t}^{e}\right)=\frac{C\left(\theta_{t}^{e}\right)}{\gamma\left(C\left(\theta_{t}^{e}\right)\right) g\left(\theta_{t}^{e}\right)}\left[r_{t}-\rho+\theta_{t}^{e}\left(\frac{u^{\prime}\left(C\left(h\left(\theta_{t}^{e}\right)\right)\right)}{u^{\prime}\left(C\left(\theta_{t}^{e}\right)\right)}-1\right)\right] .
$$


Applying (11) and (18) to (22) leads to the dynamics of $c_{t}\left(\equiv C\left(\theta_{t}^{e}\right)\right)$ while the shock does not occur

$$
\frac{\dot{c}_{t}}{c_{t}}=\frac{1}{\gamma\left(c_{t}\right)}\left[r_{t}-\rho+\theta_{t}^{e}\left(\frac{u^{\prime}\left(C\left(h\left(\theta_{t}^{e}\right)\right)\right)}{u^{\prime}\left(c_{t}\right)}-1\right)\right] \quad \text { for } t \notin S_{(0, \infty)},
$$

which is the Keynes-Ramsey rule in the present setting. Note that it is the same as the standard one except for the third term in brackets of the right-hand side. This term represents a jump in the marginal utility caused by the shock. If $c_{t}$ declines after the shock, causing the marginal utility of consumption to increase, this term is positive and thus the growth rate of $c_{t}$ is higher than would obtain in the standard Ramsey model. That is, since the representative household anticipates a possible increase in the marginal utility of consumption, it tries to reallocate consumption from the present to the future, raising the growth rate of consumption during the period without the shock.

\subsection{Choice between Consumption and Money}

Having examined the household's intertemporal optimization of consumption, we now turn to the optimal choice between consumption and money holding. By holding one unit of real money balances between time $t$ and $t+\Delta t$, the household loses $\left(r_{t}+\pi_{t}\right) \Delta t$ units of consumption, or equivalently $\left(r_{t}+\pi_{t}\right) u^{\prime}\left(c_{t}\right) \Delta t$ units in terms of utility, when compared to holding a unit of risk-free asset during this period. At this cost a one-unit increase in real money holding raises the household's utility (16) by $\beta$ if the shock occurs. Since the subjective probability that the shock occurs between $t$ and $t+\Delta t$ is $\theta_{t}^{e} \Delta t$, the increase in the expected utility is $\beta \theta_{t}^{e} \Delta t$. The marginal benefit should equal the marginal cost on the optimal path, which yields the first-order condition between money holding and consumption:

$$
r_{t}+\pi_{t}=\frac{\beta \theta_{t}^{e}}{u^{\prime}\left(c_{t}\right)} \text { for all } t
$$

Equation (24) implies the well-known property that the marginal rate of substitution between consumption and real money holding equals the nominal rate of interest.

Substituting (15) into (24) and rearranging terms yields

$$
r_{t}=\frac{\beta \theta_{t}^{e}}{u^{\prime}\left(c_{t}\right)}-f\left(c_{t}-1\right) \equiv R\left(\theta_{t}^{e}, c_{t}\right)
$$


Intuitively, function $R(\cdot)$ represents the household's preference for liquidity, defined by the expected utility gain minus capital loss from holding money for a unit of time. Given the amount of consumption, the preference for liquidity is stronger when the subjective shock probability is higher; i.e.,

$$
R_{\theta}\left(\theta^{e}, c\right) \equiv \partial R\left(\theta^{e}, c\right) / \partial \theta^{e}=\frac{\beta}{u^{\prime}\left(c_{t}\right)}>0 \quad \text { for all } \theta_{t}^{e}>0 \text { and } c_{t}>0
$$

We restrict our attention to a reasonable case where function $R(\cdot)$ in $(25)$, or equivalently utility function $u(\cdot)$ and price adjustment function $f(\cdot)$, satisfies two additional properties:

Assumption $2 \lim _{c \rightarrow 0} R\left(\theta^{H}, c\right)<\rho$ and $\lim _{c \rightarrow \infty} R\left(\theta^{*}, c\right)>\rho$.

Assumption $3 R_{c}\left(\theta^{e}, c\right)$ is continuous and positive for all $\theta^{e} \in\left[\theta^{*}, \theta^{H}\right]$ and $c>0$, where $R_{c}\left(\theta^{e}, c\right) \equiv \partial R\left(\theta^{e}, c\right) / \partial c$.

If the household's preference for liquidity, given by $R(\cdot)$, is stronger than its preference for present consumption $\rho$, it postpones consumption and holds more money. Therefore, in Assumption 2 the first condition implies that this household prefers consumption to liquidity holding when its consumption is quite low even if it expects the highest shock probability $\theta^{H}$. The second condition implies that the household prefers liquidity to consumption when its consumption is sufficiently high even if it expects the lowest shock probability $\theta^{*}$. Assumption 3 extends this relationship between $c_{t}$ and $R(\cdot)$ to a smooth and monotonic one under a given $\theta_{t}^{e}$-i.e., as consumption increases, liquidity preference rises as long as the state of expectation about the shock is unchanged.

\subsection{Stationary Dynamics}

Now we are ready to determine the pattern of stationary dynamics, represented by function $C(\cdot)$. Equation (25) requires that the rate of return from a risk-free asset (riskless bonds), $r_{t}$, should be equalized to $R(\cdot)$ for all $t$. Also, $r_{t}$ must be consistent with Euler equation 
(22). From these two equations, the optimizing household behavior is summarized as

$$
\begin{aligned}
& C^{\prime}\left(\theta_{t}^{e}\right)=\frac{C\left(\theta_{t}^{e}\right)}{\gamma\left(C\left(\theta_{t}^{e}\right)\right) g\left(\theta_{t}^{e}\right)}\left[R\left(\theta_{t}^{e}, C\left(\theta_{t}^{e}\right)\right)-\rho+\theta_{t}^{e}\left(\frac{u^{\prime}\left(C\left(h\left(\theta_{t}^{e}\right)\right)\right)}{u^{\prime}\left(C\left(\theta_{t}^{e}\right)\right)}-1\right)\right] \\
& \quad \text { for all } \theta_{t}^{e} \in\left(\theta^{*}, \theta^{H}\right] .
\end{aligned}
$$

Function $C(\cdot)$ is determined so that it satisfies differential equation $(27)$. To pin down $C(\cdot)$, however, we also need a boundary condition. If $\dot{c}_{t} / c_{t}$ remains positive as $\theta_{t}^{e}$ approaches steady-state value $\theta^{*}$, then $c_{t}$ unboundedly explodes. Conversely, if $\dot{c}_{t} / c_{t}$ remains negative as $\theta_{t}^{e} \rightarrow \theta^{*}, c_{t}$ converges to zero, violating the transversality condition. We rule out such paths by imposing a boundary condition, ${ }^{18}$

$$
\lim _{\theta^{e} \rightarrow \theta^{*}} R\left(\theta^{e}, C\left(\theta^{e}\right)\right)-\rho+\theta^{e}\left(\frac{u^{\prime}\left(C\left(h\left(\theta^{e}\right)\right)\right)}{u^{\prime}\left(C\left(\theta^{e}\right)\right)}-1\right)=0,
$$

under which $\dot{c}_{t} / c_{t}$ given by (23) approaches zero as $\theta_{t}^{e} \rightarrow \theta^{*}$.

Equations (27) and (28) determine the whole shape of $C\left(\theta_{t}^{e}\right)$ within interval $\left(\theta^{*}, \theta^{H}\right]$. Note that (27) is not a usual difference equation, but a difference-differential equation: ${ }^{19}$ the gradient of function $C(\cdot)$ at $\theta^{e}$ depends on the value of function $C(\cdot)$ not only at $\theta^{e}$, but also at $h\left(\theta^{e}\right) \neq \theta^{e}$. This is a natural consequence since an occurrence of the shock discretely changes the belief and consumption of the household, and their optimization always takes such a possibility into account. Although analysis of this type of system is not straightforward, in Appendix A we obtain its important properties: existence of the solution, its uniqueness, boundedness, and the sign of gradient of function $C\left(\theta^{e}\right)$.

Proposition 1 Under the assumptions 2 and 3, there exists a unique function $C\left(\theta^{e}\right)$ that satisfies (27) and (28). It is strictly downward sloping for any $\theta^{e} \in\left(\theta^{*}, \theta^{H}\right]$ and has positive and finite upper and lower bounds $\bar{c}$ and $\underline{c}$ that are given by

$$
R\left(\theta^{*}, \bar{c}\right)=\rho, \quad R\left(\theta^{H}, \underline{c}\right)=\rho .
$$

Proof. See Appendix A.

\footnotetext{
${ }^{18}$ Throughout this paper we use operator 'lim' to denote the right-hand limit.

${ }^{19}$ It is also called a delay difference equation.
} 
Proposition 1 states that there is a negative relationship between belief $\theta_{t}^{e}$ and consumption $c_{t}=C\left(\theta_{t}^{e}\right)$. When the subjective probability of the shock $\theta_{t}^{e}$ rises, the expected benefit of holding money increases, and therefore the household reduces consumption. Also, there is an endogenous dynamic mechanism that reinforces this relationship. Since a higher subjective probability of the shock $\theta_{t}^{e}$ reduces consumption $C\left(\theta_{t}^{e}\right)$, labor demand declines, and hence the inflation rate falls. It reduces the cost of holding money, and therefore further strengthens the liquidity preference. ${ }^{20}$ Furthermore, the household understands that their income (= aggregate consumption) $C\left(\theta_{t}^{e}\right)$ will fall discretely if a shock occurs in the future. Therefore, a higher subjective possibility of a liquidity shock $\theta_{t}^{e}$ leads to a stronger incentive to save current income in the form of money. ${ }^{21}$ In this way, the fact that function $C(\cdot)$ is downward sloping further strengthens the effect of the belief of the household on liquidity preference and consumption.

\section{Time Evolution of the Economy}

Utilizing the results obtained in the previous sections, this section considers the time evolution of aggregate real variables in the economy. We first show that the pattern of evolution of the economy is characterized by sporadic falls in consumption and output, followed by gradual recovery toward a steady-state level. Following this, we examine the speed of the recovery process.

Recall that, in Section 2, we have shown that the time path of belief $\theta_{t}^{e}$ is uniquely determined by initial belief $\theta_{0}^{e}$ and the history of the liquidity shock $S_{(0, t]}$. Then, in Section 3 , we have derived a mapping from belief $\theta_{t}^{e}$ to consumption $c_{t}$. Combining those results naturally gives the time path of $c_{t}$. For concreteness, let us consider log utility function

\footnotetext{
${ }^{20}$ Observe that equation (25) is increasing in $c_{t}$. Strictly speaking, there is also an opposing effect since a fall in consumption increases the marginal utility from consumption, and therefore reduces the preference for money relative to consumption. In Assumption 3, we assumed that the latter effect is weaker than the positive effect explained in the text.

${ }^{21}$ This is confirmed from the fact that the additional term in the modified Keynes-Ramsey equation (23) is positive.
} 


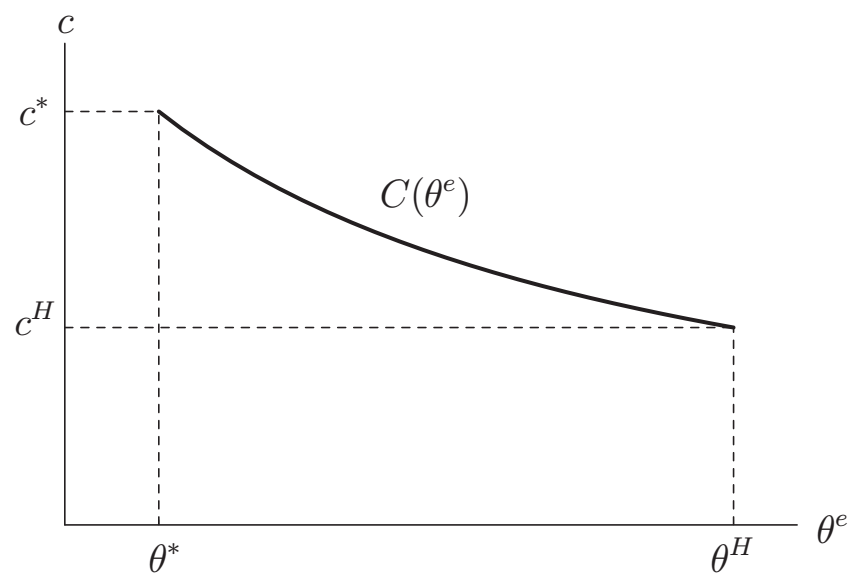

Figure 3: A typical shape of function $C\left(\theta_{t}^{e}\right)$. Parameters: $\theta^{H}=.4, \theta^{L}=.05, p^{H}=.025, p^{L}=.1$, $\rho=.05, \alpha=.025$, and $\beta=.4$. Under these parameter values, we obtain $\theta^{*} \approx .069, c^{*} \approx 1.3$ and $c^{H} \approx .60$.

$u\left(c_{t}\right)=\log c_{t}$ and a linear Phillips curve $\pi_{t}=f\left(c_{t}-1\right)=\alpha \cdot\left(c_{t}-1\right)$, where $\alpha>0$ is a constant. In this setting, Assumptions 2 and 3 simplify to $\beta \theta^{*}>\alpha$ and $\rho>\alpha$, respectively. ${ }^{22}$ Then, choosing parameter values so that these conditions as well as Assumption 1 are satisfied, we can numerically calculate the shape of function $C(\cdot)$. Figure 3 illustrates a typical shape of the function (Details of the numerical procedure are described in Appendix B.) It confirms the statement of Proposition 1 that the curve is downward sloping and ranges between finite values, $c^{*} \equiv C\left(\theta^{*}\right)$ and $c^{H} \equiv C\left(\theta^{H}\right)$.

As the belief of the household $\theta_{t}^{e}$ changes, the amount of consumption, and therefore aggregate output, move along this curve. As discussed in Section 2, the law of motion for belief $\theta_{t}^{e}$ is different depending on whether a shock is observed or not at a particular point in time $t$. For most of the time, the household does not observe a shock, and belief $\theta_{t}^{e}$ follows a deterministic path given by (11). As illustrated in Figure 1, the time derivative of $\theta_{t}^{e}$ is negative for any $\left(\theta^{*}, \theta^{H}\right]$, implying that subjective shock probability

\footnotetext{
${ }^{22}$ Using a money-in-utility model without uncertainty, Ono (1994, pp.86-88; 2001) shows that in the case where $\beta>\alpha$ and $\rho>\alpha$ there is a unique saddle-stable path. Furthermore, the path accommodates a persistent demand shortage when $\rho<\beta$, whereas it reaches a full-employment steady state when $\rho>\beta$. The present condition is the same as Ono's condition except that the former includes the shock probability $\theta^{*}$.
} 


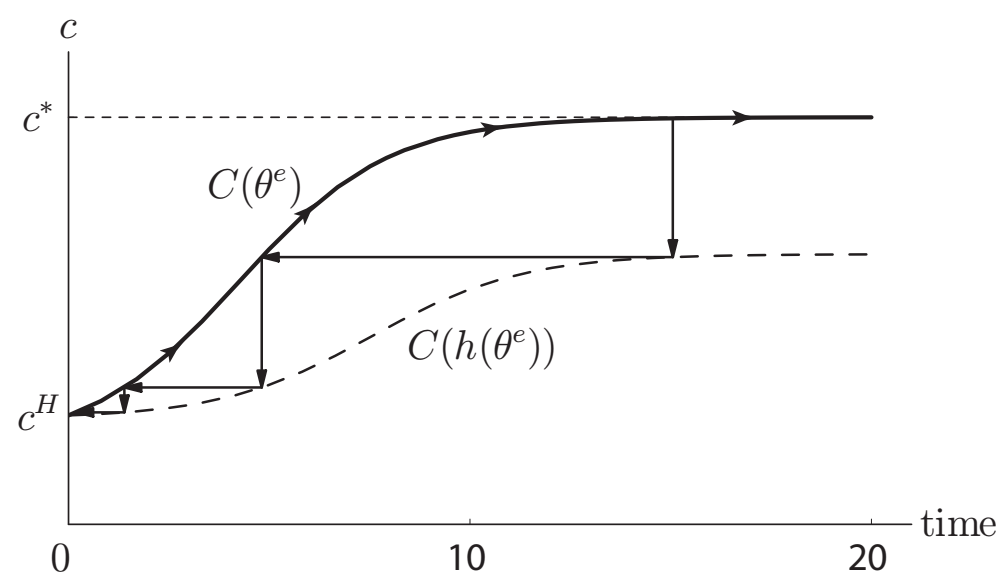

Figure 4: Time path of consumption recovery. This figure is obtained in two steps. First, the time path of $\theta_{t}^{e}$ is calculated by integrating (11) with respect to time. Second, the calculated time paths of $\theta_{t}^{e}$ and $h\left(\theta_{t}^{e}\right)$ are applied to function $C(\cdot)$, which is numerically calculated as in Figure 3. Parameters are the same as in Figure 3.

$\theta_{t}^{e}$ gradually falls toward $\theta^{*}$. Thus, the preference for liquidity gradually declines and consumption grows toward $c^{*} \equiv C\left(\theta^{*}\right)$ since function $C(\cdot)$ is downward sloping. Conversely, at discrete points in time, the household observes a shock and discretely increases $\theta_{t}^{e}$ according to (11). Since function $C(\cdot)$ is downward sloping, this causes a downward jump in consumption. As illustrated in Figure 2, belief $\theta_{t}^{e}$ approaches $\theta^{H}$ when shocks occur in succession. Accordingly, consumption can fall to $c^{H} \equiv C\left(\theta^{H}\right)$. Since the shock occurs (only) at sporadic points in time, the economy experiences sporadic falls and gradual recoveries in consumption and output. In this way, $c_{t}$ persistently fluctuates within finite interval $\left[c^{H}, c^{*}\right]$.

The speed at which consumption recovers toward the steady-state level $c^{*}$ depends on how quickly the household changes its beliefs. The solid curve in Figure 4 depicts the time evolution of $c_{t}$, assuming that $c_{t}$ starts from the lowest level $c^{H}$ and that no shock occurs after that. Observe that consumption first grows slowly, gradually accelerates, and eventually slows down again as it approaches $c^{*}$-i.e., it traces an S-shaped trajectory.

To see why $c_{t}$ follows the S-shaped trajectory, recall that the time derivative of $\theta_{t}^{e}$ is given by U-shape function $\dot{\theta}_{t}^{e}=g\left(\theta_{t}^{e}\right)$, as depicted in Figure 1 . We can interpret the 
dynamics in three phases.

1. When people strongly believe that they are in state $H$ and thus $\theta_{t}^{e}$ is very close to $\theta^{H}$, then Figure 1 shows that $\left|g\left(\theta_{t}^{e}\right)\right|$ is small. This implies that they do not significantly alter their pessimistic view for a while, and therefore consumption increases only slowly.

2. As the period without the shock lasts, $\theta_{t}^{e}$ decreases and $\left|g\left(\theta_{t}^{e}\right)\right|$ increases. As their belief gets weaker, they become more willing to revise it based upon the fact that they do not observe shocks for a while, and therefore $\theta_{t}^{e}$ declines more quickly. Accordingly, the recovery speed of consumption accelerates.

3. As $\theta_{t}^{e}$ approaches to steady-state value $\theta^{*}$, people become quite confident that they are in state L, and hence an additional period without the shock provides little information. Therefore, $\left|g\left(\theta_{t}^{e}\right)\right|$ falls to zero and the growth of consumption slows down.

Figure 4 shows that $c_{t}$ recovers toward $c^{*}$ in the absense of liquidity shocks. However, a liquidity shock will certainly occur before $c_{t}$ reaches $c^{*}$. At the moment the shock is observed, consumption falls from $C\left(\theta_{t}^{e}\right)$ to $C\left(h\left(\theta_{t}^{e}\right)\right)$, as depicted by vertical arrows in Figure 4. Then, the recovery process 'restarts' from the point that corresponds to the decreased level of consumption (as indicated by horizontal arrows) and consumption again traces the solid curve. Note that a single shock can only send $c_{t}$ from $c^{*}$ to an intermediate value, from where the economy can recover relatively quickly. However, if the shocks occur repeatedly, the subjective probability successively increases, and $C\left(\theta_{t}^{e}\right)$ approaches the lowest level $c^{H}$. After the shocks cease, consumption recovers along the S-shaped trajectory, as explained above.

Figure 5 presents an example of the realized time paths of $\theta_{t}, \theta_{t}^{e}$ and $c_{t}$, which are obtained by simulating the Markov process of the underlying state and the Poisson process for the shock. Consumption in fact traces an S-shaped path, especially after a bunch of liquidity shocks make it close to the lowest value $c^{H}$. 

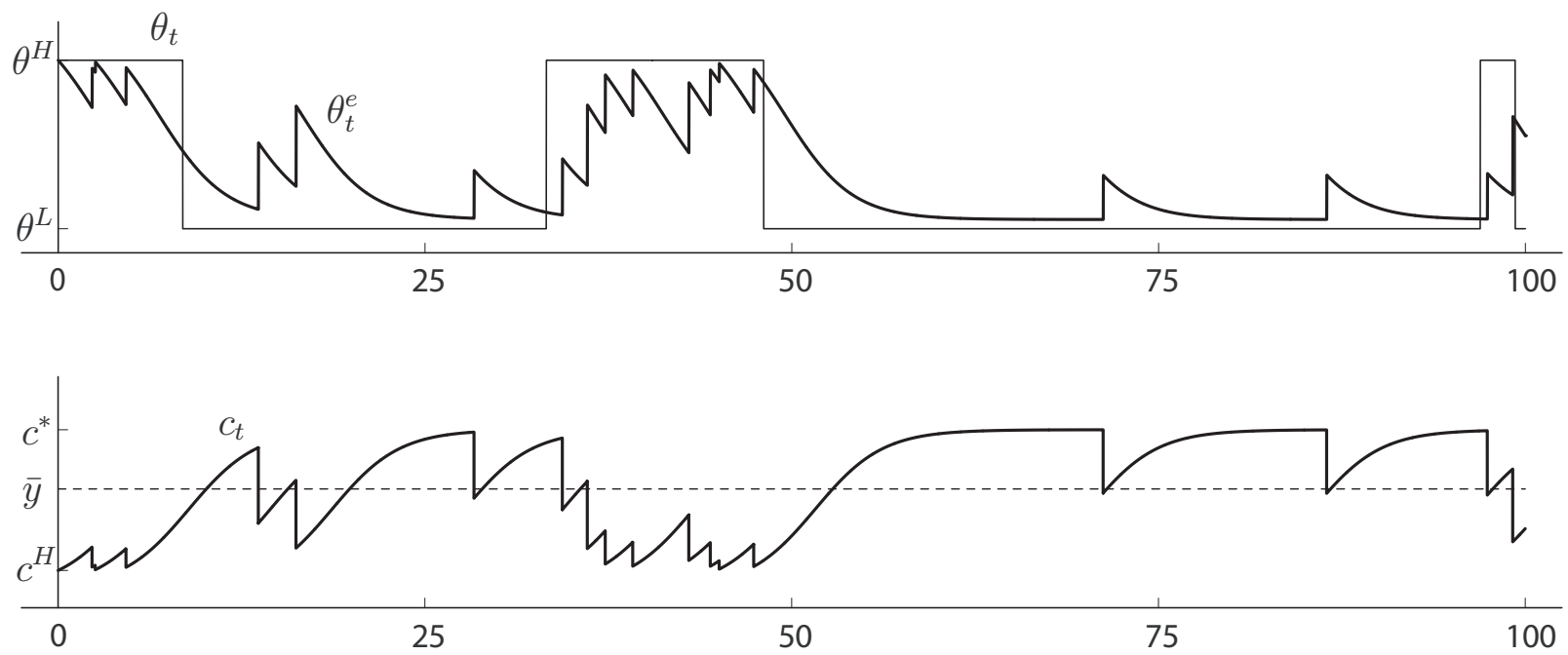

Figure 5: An example of the realized paths of actual state $\theta_{t}$, belief $\theta_{t}^{e}$, and consumption $c_{t}$. Parameters are the same as in Figure 3.

Before closing this section, let us briefly consider the effect of the household's belief on other assets than money. On the equilibrium path, the expected rate of return from any asset should be adjusted so that the household is always indifferent between holding money and any other assets. In particular, as shown in equation (24), the nominal interest rate on a risk-free asset should coincide with the expected benefit from money holding. On the equilibrium path, the latter is a function of the household's belief and can be written as $\beta \theta_{t}^{e} / u^{\prime}\left(C\left(\theta_{t}^{e}\right)\right)$. When the household observes a shock, its subjective shock probability $\theta^{e}$ rises and consumption $C\left(\theta_{t}^{e}\right)$ falls. As a result, both expected utility from money holding $\beta \theta_{t}^{e}$ and marginal utility from consumption $u^{\prime}\left(C\left(\theta_{t}^{e}\right)\right)$ rise, making the net effect of a higher $\theta_{t}^{e}$ on the nominal interest rate ambiguous. Nonetheless, the real interest rate tends to be upward sloping in $\theta_{t}^{e}$, because the reduced aggregate consumption pushes down the inflation rate. More precisely, we can show that $r_{t}$ is necessarily higher when $\theta_{t}^{e}$ is at its highest level $\theta^{H}$ than when it is at its lowest level $\theta^{*}$ : From $R_{c}>0$ and Proposition 1, $R\left(\theta^{*}, C\left(\theta^{*}\right)\right)<R\left(\theta^{*}, \bar{c}\right)=\rho=R\left(\theta^{H}, \underline{c}\right)<R\left(\theta^{H}, C\left(\theta^{H}\right)\right)$. 


\section{Discussion: The Role of the Learning Process}

So far, we have explained the movements of aggregate variables in terms of the information brought by the realized shocks. Note that an occurrence of the shock is a piece of relevant information, and therefore has a real effect on the aggregate economy because the household does not know the actual state of the economy. If households precisely know the actual state, occurrences of the shock do not alter their belief or behavior.

Then, why cannot the household learn the true state even in the long run? If the true state of the economy, $\theta_{t}$, is constant, cumulative observations of the shock will eventually reveal the true state (i.e., $\theta_{t}^{e} \rightarrow \theta_{t}$ ), and further occurrences of the shock do not affect the household's beliefs and their behavior. In the economy considered, however, the true state changes over time in an unobservable way, which prevents complete learning. In this sense, the source of persistent fluctuations in economic variables is stochastic movements in the actual underlying state.

Nonetheless, the learning process plays an essential role in generating the previously described pattern of aggregate movements. To see this, suppose that the household can directly observe true state $\theta_{t}$. This means that there is no learning process, and trivially $\theta_{t}^{e}=\theta_{t}$. Recall that $\theta_{t}^{e}=\theta_{t}$ takes either $\theta^{H}$ or $\theta^{L}$. Since the discussion in Section 3.2 is still valid in this case, equation (18) implies that on the stationary path, $c_{t}$ takes only two values. Let us denote them again by $C\left(\theta^{H}\right) \equiv c^{H}$ and $C\left(\theta^{L}\right) \equiv c^{L}$, although their values differs from those in Section 3. From the optimization of the household (analogous to the analysis in Section 3.3 and Section 3.4), it can be shown that $c^{H}$ and $c^{L}$ are given as a solution to certain simultaneous equations, and that $c^{H}$ is smaller than $c^{L} \cdot{ }^{23}$ This

${ }^{23}$ In particular, $c^{H}$ and $c^{L}$ must satisfy

$$
p^{H} \frac{u^{\prime}\left(c^{H}\right)-u^{\prime}\left(c^{L}\right)}{u^{\prime}\left(c^{H}\right)}=R\left(\theta^{H}, c^{H}\right)-\rho, \quad \text { and } \quad p^{L} \frac{u^{\prime}\left(c^{L}\right)-u^{\prime}\left(c^{H}\right)}{u^{\prime}\left(c^{L}\right)}=R\left(\theta^{L}, c^{L}\right)-\rho,
$$

where the LHS of each equation represents the expected growth rate of the marginal utility due to the stochastic movement of the underlying state, and the RHS represents the deviation of the risk free rate from the rate of time preference. From these equations, it can be easily confirmed that Assumption 3 will be violated if $c^{H} \geq c^{L}$. 
means that the behavior of households correspond one-to-one with the underlying state: once they observe that the economy switches to state $\mathrm{H}(\mathrm{L})$, they immediately increase (decrease) liquidity preference and decrease (increase) consumption.

In contrast, when households cannot directly observe the underlying state, realized booms and depressions do not precisely match the underlying state of the economy but follow the subjective probability that people have in mind (see Figure 5). Even when the economy switches to state $\mathrm{H}$, and thus the actual probability of the shock jumps up, people do not increase liquidity preference until they observe the shock. Similarly, even when the true shock probability jumps down, they still retain a strong liquidity preference for a while.

More importantly, the learning process creates an asymmetry between the fall and recovery of consumption. The fall of consumption occurs as soon as people observe a shock. In contrast, the recovery is only gradual, especially once they become very pessimistic. This pattern applies even when underlying $\theta_{t}$ follows a symmetric Markov process (i.e., when $p^{H}=p^{L}$ ). The aggregate movements have the asymmetric pattern because an occurrence of the shock has a discrete amount of information, and this information is always a "bad news" in our model. In other words, the safer state (state L) is revealed only on the basis of "no news is good news." This is why recovery occurs only gradually.

It is for the sake of simplicity that we considered only one type of shock, which delivers information that favors less consumption. As well as bad news, we sometimes hear the good news that delivers discrete amounts of positive information, e.g., a discovery of a breakthrough technology that might boost aggregate productivity. In a model that incorporates a positive signal, a rise of consumption (or a rise of investment, depending on the model) would occur immediately after the signal is received. Consumption would gradually fall when people do not receive such a signal for a while. An important task for further work would be to study the relative importance of positive and negative discrete signals in the real economy, or, more specifically, their frequency and the amounts of information brought by their occurrences. 


\section{Conclusion}

Liquidity preference depends on people's belief about how frequently they encounter crises. This paper has examined the way they update the belief based on Bayesian inference and its effect on their preference for liquidity holding relative to consumption. The analysis is done in a circumstance where the economy shifts between two unobservable states with different probabilities of the liquidity shock. Each time they observe the shock, they raise their subjective probability of being in the less stable state and increase the liquidity preference. The longer the period without the shock lasts, the larger the probability people attach to the safer state and increase preference for consumption over money holdings. With incomplete nominal wage adjustment, such movements in liquidity preference produce fluctuations in aggregate consumption and output.

Even when the underlying state of the economy follows a symmetric Markov process, the pattern of fluctuations in aggregate variables is not symmetric. The fall occurs immediately after observing the shock, whereas the recovery is gradual. Also, the speed of the recovery process depends on the realized frequency of the shock. As long as the shock sparsely occurs in time, it has only a minor effect on the belief, and hence the economic recovery is relatively quick. However, if people observe the shock many times over a short period, they hold a strong belief of being in the less stable state and reduce consumption considerably. Once that occurs, it takes a long time for them to reverse their belief and increase consumption. In this process, the recovery speed is first slow, then gradually accelerates and eventually settles down, tracing an S-shaped curve.

The asymmetry occurs because the occurrence of a shock is a discrete event, while the recovery is realized only by "no news is a good news," which takes time. To highlight this difference, we employed a continuous-time model of Bayesian learning, while most preceding models of business cycles are developed in discrete-time settings. Although our strategy was beneficial in making an intuitive explanation of the asymmetry, there are some limitations. In particular, because we need to solve the continuous-time dynamics with the possibility of jumps, the model will become quickly intractable if we incorporate 
various factors that are common in linearized DSGE models.

To address the technical difficulty, we chose to make two simplifying assumptions in this paper. First, we assumed a reduced-form relationship between the inflation rate and the output gap, rather than explicitly specifying the process of price adjustments. Second, the stochastic money-in-utility function in our model (equation 16) did not incorporate the diminishing returns to money holdings. The latter simplification enabled us to derive the consumption function that depends only on their belief, $C\left(\theta_{t}^{e}\right)$. However, by this assumption, the current analysis in effect abstracted from the role played the amount of money supply. Still, we believe that our mechanism of learning in a continuous-time setting gives an intuitive explanation of business cycle asymmetry and slow recovery, especially when the cycle is driven by discrete events, such as a sudden collapse of key financial institutions. We hope this paper serves as a starting point for future work that relaxes the limitations.

\section{Appendix A: Proof of Proposition 1}

\section{Proof of $C(\theta)$ to be downward sloping}

In the appendices we use $\theta$ instead of $\theta_{t}^{e}$ to minimize notation. Before starting the proof we define function $D(\theta)$ by

$$
D(\theta) \equiv R(\theta, C(\theta))-\rho+\theta\left(\frac{u^{\prime}(C(h(\theta)))}{u^{\prime}(C(\theta))}-1\right) .
$$

Since $D(\theta)$ is the expression in brackets of (27) and (11) shows $g(\theta)$ to be negative for all $\theta \in$ $\left(\theta^{*}, \theta^{H}\right]$,

$$
C^{\prime}(\theta) \lesseqgtr 0 \Longleftrightarrow D(\theta) \gtreqless 0 \text {. }
$$

Using function $D(\theta)$ we first prove

Lemma 1 Suppose that $C(\theta)$ satisfies (27) and that there exists $\theta^{0} \in\left[\theta^{*}, \theta^{H}\right)$ satisfying $\lim _{\theta \rightarrow \theta^{0}} D(\theta)=$ 0. Then, under Assumption 3, $C(\theta)$ is strictly downward sloping for all $\theta \in\left(\theta^{0}, \theta^{H}\right]$.

Proof: If Lemma 1 does not hold and hence $C(\cdot)$ is weakly upward sloping somewhere in $\left(\theta^{0}, \theta^{H}\right]$, either of the following must be the case. 
(i) There exists some $\theta^{A} \in\left[\theta^{0}, \theta^{H}\right)$ such that $\lim _{\theta \rightarrow \theta^{A}} D(\theta)=0$ and $C^{\prime}(\theta) \geq 0$ for all $\theta \in\left(\theta^{A}, \theta^{H}\right]$.

(ii) There exists some $\theta^{A} \in\left[\theta^{0}, \theta^{H}\right)$ and $\theta^{B} \in\left(\theta^{A}, \theta^{H}\right)$ such that $\lim _{\theta \rightarrow \theta^{A}} D(\theta)=D\left(\theta^{B}\right)=0$, $C^{\prime}(\theta) \geq 0$ for all $\theta \in\left(\theta^{A}, \theta^{B}\right]$, and $C^{\prime}(\theta) \leq 0$ for all $\theta \in\left(\theta^{B}, \theta^{H}\right]$.

Intuitively, if the lemma is false, we can choose an interval $\left(\theta^{A}, \theta^{B}\right]$ in which function $C(\theta)$ is weakly increasing, $\theta^{A}$ is either a local minimum or $\theta^{0}$, and $\theta^{B}$ is either a local maximum or $\theta^{H}$. If there are multiple intervals of that, we choose the rightmost one. We shall find neither (i) nor (ii) to be valid.

We first show that case (i) leads to a contradiction. Since $R_{c}>0$ from Assumption 3 and $R_{\theta}>0$ from (26), in case (i),

$$
\lim _{\theta \rightarrow \theta^{A}} R(C(\theta), \theta)<R\left(C\left(\theta^{H}\right), \theta^{H}\right) .
$$

Since $h\left(\theta^{A}\right) \in\left(\theta^{A}, \theta^{H}\right), \lim _{\theta \rightarrow \theta^{A}} C(\theta) \leq C\left(h\left(\theta^{A}\right)\right)$ whereas $C\left(\theta^{H}\right)=C\left(h\left(\theta^{H}\right)\right)$ since $h\left(\theta^{H}\right)=\theta^{H}$ from (13). Since applying these properties and (32) to (30) implies $0=\lim _{\theta \rightarrow \theta^{A}} D(\theta)<D\left(\theta^{H}\right)$ in case (i), from (31) we find $C^{\prime}\left(\theta^{H}\right)<0$, which contradicts (i).

In case (ii) $\lim _{\theta \rightarrow \theta^{A}} C(\theta) \leq C\left(\theta^{B}\right)$. Since $R_{c}>0$ from Assumption 3 and $R_{\theta}>0$ from (26), this inequality implies

$$
\lim _{\theta \rightarrow \theta^{A}} R(C(\theta), \theta)<R\left(C\left(\theta^{B}\right), \theta^{B}\right) .
$$

Further, $h\left(\theta^{A}\right)$ is located in either $\left(\theta^{A}, \theta^{B}\right]$ or $\left(\theta^{B}, \theta^{H}\right)$. If $h\left(\theta^{A}\right) \in\left(\theta^{A}, \theta^{B}\right]$, then $C\left(h\left(\theta^{A}\right)\right) \geq$ $\lim _{\theta \rightarrow \theta^{A}} C(\theta)$ since we suppose $C^{\prime}(\theta) \geq 0$ for all $\theta \in\left(\theta^{A}, \theta^{B}\right]$. In contrast, $C\left(h\left(\theta^{B}\right)\right) \leq C\left(\theta^{B}\right)$ since $h\left(\theta^{B}\right) \in\left(\theta^{B}, \theta^{H}\right)$ and $C^{\prime}(\theta) \leq 0$ for all $\theta \in\left(\theta^{B}, \theta^{H}\right]$. Using these inequalities, (30) and (33) we find $\lim _{\theta \rightarrow \theta^{A}} D(\theta)<D\left(\theta^{B}\right)$, which contradicts case (ii).

If $h\left(\theta^{A}\right) \in\left(\theta^{B}, \theta^{H}\right)$, then because $h^{\prime}(\theta)>0$ from (13), we find $\theta^{A}<\theta^{B}<h\left(\theta^{A}\right)<h\left(\theta^{B}\right)<$ $\theta^{H}$. In case (ii), this means

$$
\lim _{\theta \rightarrow \theta^{A}} C(\theta) \leq C\left(\theta^{B}\right) \geq C\left(h\left(\theta^{A}\right)\right) \geq C\left(h\left(\theta^{B}\right)\right) .
$$

Thus,

$$
\frac{u^{\prime}\left(C\left(h\left(\theta^{B}\right)\right)\right)}{u^{\prime}\left(C\left(\theta^{B}\right)\right)}-1 \geq \max \left(0, \lim _{\theta \rightarrow \theta^{A}} \frac{u^{\prime}(C(h(\theta)))}{u^{\prime}(C(\theta))}-1\right) .
$$

Applying this property and (33) to (30) yields $\lim _{\theta \rightarrow \theta^{A}} D(\theta)<D\left(\theta^{B}\right)$, which contradicts case (ii). Thus, anyway case (ii) results in a contradiction. 
From (30), boundary condition (28) is equivalent to $\lim _{\theta \rightarrow \theta^{*}} D(\theta)=0$. By regarding $\theta^{*}$ as $\theta^{0}$ in Lemma 1 , we find $C(\theta)$ that satisfies $(27)$ and (28) to be strictly downward sloping for all $\theta \in\left(\theta^{*}, \theta^{H}\right]$.

\section{The existence of upper and lower bounds for $C(\theta)$}

We first show $\bar{c}$ and $\underline{c}$ to be unique and well defined. Since $\theta^{*}<\theta^{H}$ and $R_{\theta}>0$ from (26), under Assumption 2,

$$
\lim _{c \rightarrow 0} R\left(\theta^{*}, c\right) \leq \lim _{c \rightarrow 0} R\left(\theta^{H}, c\right)<\rho<\lim _{c \rightarrow \infty} R\left(\theta^{*}, c\right) \leq \lim _{c \rightarrow \infty} R\left(\theta^{H}, c\right) .
$$

Applying this property and Assumption 3 to the intermediate value theorem implies that there are unique and positive $\underline{c}$ and $\bar{c}$ satisfying (29). Furthermore, since $R\left(\theta^{H}, \bar{c}\right)>R\left(\theta^{*}, \bar{c}\right)=\rho=$ $R\left(\theta^{H}, \underline{c}\right)$, Assumption 3 implies $\bar{c}>\underline{c}$.

Next, we prove the following lemma.

Lemma 2 Suppose that $C(\theta)$ satisfies (27) and that there exists $\theta^{0} \in\left[\theta^{*}, \theta^{H}\right)$ satisfying $\lim _{\theta \rightarrow \theta^{0}} D(\theta)=$ 0. Then, under Assumptions 2 and 3, $C(\theta) \in[\underline{c}, \bar{c}]$ for all $\theta \in\left(\theta^{0}, \theta^{H}\right]$.

Proof: As shown by Lemma 1, the last term in (30) is positive when $\theta \rightarrow \theta^{0}$ and hence

$$
\lim _{\theta \rightarrow \theta^{0}} R(\theta, C(\theta))<\rho
$$

From the first equation of (29), (26), and Assumption $3, R(\theta, c)>\rho$ for all $\theta \in\left[\theta^{*}, \theta^{H}\right]$ and $c>\bar{c}$. Thus, (34) implies $\lim _{\theta \rightarrow \theta^{0}} C(\theta) \leq \bar{c}$.

When $\theta=\theta^{H}$, the last term in (30) equals zero since $h\left(\theta^{H}\right)=\theta^{H}$ from (13). Since $C^{\prime}\left(\theta^{H}\right) \leq 0$ from Lemma 1, (31) implies $D\left(\theta^{H}\right) \geq 0$. Applying these properties to (30) yields

$$
R\left(\theta^{H}, C\left(\theta^{H}\right)\right) \geq \rho
$$

Comparing this property with the second equation of (29) and using Assumption 3 yield $C\left(\theta^{H}\right) \geq$ c. Furthermore, the monotonicity of $C(\theta)$ from Lemma 1 implies $C(\theta) \in\left[C\left(\theta^{H}\right), \lim _{\theta \rightarrow \theta^{0}} C(\theta)\right] \subseteq$ $[\underline{c}, \bar{c}]$ for all $\theta \in\left(\theta^{0}, \theta^{H}\right]$.

Under condition (28), $\theta^{*}$ satisfies the requirement for $\theta^{0}$ in Lemma 2. Thus, $C(\theta) \in[\underline{c}, \bar{c}]$ for all $\theta \in\left(\theta^{*}, \theta^{H}\right]$. 


\section{The uniqueness of $C(\theta)$}

Let $\widetilde{C}\left(\theta, c^{H}\right)$ be the solution to differential equation (27) that satisfies the following boundary condition:

$$
\widetilde{C}\left(\theta^{H}, c^{H}\right)=c^{H},
$$

where $c^{H}(>0)$ is an arbitrary constant. We can solve differential equation (27) backward from $\theta=\theta^{H}$ with boundary condition (35), because $h(\theta)$ is larger than $\theta$ and thus $C(\theta)$ and $C(h(\theta))$ are already known when we calculate the gradient of $C(\cdot)$ at $\theta \cdot{ }^{24}$ Therefore, function $\widetilde{C}\left(\theta, c^{H}\right)$ is uniquely determined within interval $\left(\theta^{*}, \theta^{H}\right]$.

Using function $\widetilde{C}(\cdot)$, boundary condition (28) can be rewritten as

$$
\begin{aligned}
& \lim _{\theta \rightarrow \theta^{*}} \widetilde{D}\left(\theta, c^{H}\right)=0, \text { where } \\
& \widetilde{D}\left(\theta, c^{H}\right) \equiv R\left(\theta, \widetilde{C}\left(\theta, c^{H}\right)\right)-\rho+\theta\left(\frac{u^{\prime}\left(\widetilde{C}\left(h(\theta), c^{H}\right)\right)}{u^{\prime}\left(\widetilde{C}\left(\theta, c^{H}\right)\right)}-1\right) .
\end{aligned}
$$

$\widetilde{D}\left(\theta, c^{H}\right)$ is the expression in brackets of $(27)$ with $C(\theta)$ being replaced by $\widetilde{C}\left(\theta, c^{H}\right)$. Functions $\widetilde{C}(\cdot)$ and $\widetilde{D}(\cdot)$ have the following properties. ${ }^{25}$

Lemma 3 Under Assumption 3, (a) $\widetilde{C}_{c}\left(\theta, c^{H}\right)>0$ and (b) $\widetilde{D}_{c}\left(\theta, c^{H}\right)>0$ for all $\theta \in\left(\theta^{*}, \theta^{H}\right]$ and $c^{H}>0$. In addition, (c) there is a constant, $\underline{D_{c}}$, such that $\widetilde{D}_{c}\left(\theta, c^{H}\right)>\underline{D_{c}}>0$ whenever $\widetilde{C}\left(\theta, c^{H}\right) \in[\underline{c}, \bar{c}]$.

Proof: By rearranging terms in (27),

$$
\begin{gathered}
\widetilde{D}\left(\theta, c^{H}\right)=g(\theta) \frac{\gamma\left(\widetilde{C}\left(\theta, c^{H}\right)\right) \widetilde{C}_{\theta}\left(\theta, c^{H}\right)}{\widetilde{C}\left(\theta, c^{H}\right)}=-g(\theta) M_{\theta}\left(\theta, c^{H}\right) \\
\text { where } \quad M\left(\theta, c^{H}\right) \equiv \ln u^{\prime}\left(\widetilde{C}\left(\theta, c^{H}\right)\right)
\end{gathered}
$$

Differentiating (38) with respect to $c^{H}$ yields

$$
M_{\theta c}\left(\theta, c^{H}\right)=-\widetilde{D}_{c}\left(\theta, c^{H}\right) / g(\theta) .
$$

\footnotetext{
${ }^{24}$ The numerical analysis follows from this and is given in Appendix B.

${ }^{25} \widetilde{C}_{c}\left(\theta, c^{H}\right) \equiv \partial \widetilde{C}\left(\theta, c^{H}\right) / \partial c^{H} . \widetilde{D}_{c}\left(\theta, c^{H}\right)$ and other partial derivatives are defined likewise.
} 
Differentiating (37) with respect to $c^{H}$ gives

$$
\begin{aligned}
\widetilde{D}_{c}\left(\theta, c^{H}\right) & =\Phi\left(\theta, c^{H}\right)+\Psi\left(\theta, c^{H}\right), \text { where } \\
\Phi\left(\theta, c^{H}\right) & \equiv R_{c}\left(\theta, \widetilde{C}\left(\theta, c^{H}\right)\right) \frac{u^{\prime}\left(\widetilde{C}\left(\theta, c^{H}\right)\right)}{u^{\prime \prime}\left(\widetilde{C}\left(\theta, c^{H}\right)\right)} M_{c}\left(\theta, c^{H}\right), \\
\Psi\left(\theta, c^{H}\right) & \equiv \theta \frac{u^{\prime}\left(\widetilde{C}\left(h(\theta), c^{H}\right)\right)}{u^{\prime}\left(\widetilde{C}\left(\theta, c^{H}\right)\right)}\left(M_{c}\left(h(\theta), c^{H}\right)-M_{c}\left(\theta, c^{H}\right)\right) .
\end{aligned}
$$

Since (35) implies $\widetilde{C}_{c}\left(\theta^{H}, c^{H}\right)=1$, differentiating (39) with respect to $c^{H}$ yields

$$
M_{c}\left(\theta^{H}, c^{H}\right)=u^{\prime \prime}\left(c^{H}\right) / u^{\prime}\left(c^{H}\right)<0
$$

From (13), $h\left(\theta^{H}\right)=\theta^{H}$ and thus $\Psi\left(\theta^{H}, c^{H}\right)=0$. Using this property, Assumption 3, (35), (41) and (42) we obtain

$$
\widetilde{D}_{c}\left(\theta^{H}, c^{H}\right)=R_{c}\left(\theta^{H}, c^{H}\right)>0 .
$$

Now we extend this property to all $\theta \in\left(\theta^{*}, \theta^{H}\right]$. To prove this, suppose otherwise. Then, there should be some $\theta^{A} \in\left(\theta^{*}, \theta^{H}\right)$ that satisfies $\widetilde{D}_{c}\left(\theta, c^{H}\right)>0$ for all $\theta \in\left(\theta^{A}, \theta^{H}\right]$ and $\widetilde{D}_{c}\left(\theta^{A}, c^{H}\right) \leq 0$. This property, combined with (40), (42) and the negativity of $g(\theta)$ from (11), gives

$$
\begin{aligned}
M_{c}\left(\theta^{A}, c^{H}\right) & =M_{c}\left(\theta^{H}, c^{H}\right)+\int_{\theta^{A}}^{\theta^{H}} \widetilde{D}_{c}\left(\theta, c^{H}\right) / g(\theta) d \theta \\
& <u^{\prime \prime}\left(c^{H}\right) / u^{\prime}\left(c^{H}\right)<0 .
\end{aligned}
$$

Assumption 3, (41) and (43) imply $\Phi\left(\theta^{A}, c^{H}\right)>0$. Similarly, from (40),

$$
M_{c}\left(h\left(\theta^{A}\right), c^{H}\right)-M_{c}\left(\theta^{A}, c^{H}\right)=-\int_{\theta^{A}}^{h\left(\theta^{A}\right)} \widetilde{D}_{c}\left(\theta, c^{H}\right) / g(\theta) d \theta>0,
$$

which means $\Psi\left(\theta^{A}, c^{H}\right)>0$. Substituting these results into (41) yields $\widetilde{D}_{c}\left(\theta^{A}, c^{H}\right)>0$, which contradicts the assumption that $\widetilde{D}_{c}\left(\theta^{A}, c^{H}\right) \leq 0$. Thus there is no such $\theta^{A}$, and therefore property (b) holds.

Property (b) and (40) imply

$$
M_{\theta c}\left(\theta, c^{H}\right)>0 \text { for all } \theta \in\left(\theta^{*}, \theta^{H}\right] \text { and } c^{H}>0
$$

From (42) and (45),

$$
M_{c}\left(\theta, c^{H}\right)<u^{\prime \prime}\left(c^{H}\right) / u^{\prime}\left(c^{H}\right)<0 \text { for all } \theta \in\left(\theta^{*}, \theta^{H}\right] .
$$

Since (46) is equivalent to $\widetilde{C}_{c}\left(\theta, c^{H}\right)>0$ from (39), property $(a)$ holds. 
Finally we prove property $(c)$. Define

$$
\underline{\Phi}(\theta, c) \equiv R_{c}(\theta, c) \frac{u^{\prime}(c) u^{\prime \prime}\left(c^{H}\right)}{u^{\prime \prime}(c) u^{\prime}\left(c^{H}\right)} .
$$

From Assumption 3, $\underline{\Phi}(\theta, c)$ is positive and continuous for all $(\theta, c) \in \Theta \equiv\left[\theta^{*}, \theta^{H}\right] \times[\underline{c}, \bar{c}]$. Since $\Theta$ is a compact set, there exists $\underline{D_{c}} \equiv \min _{(\theta, c) \in \Theta} \underline{\Phi}(\theta, c)>0$. Combined with (41), (45) and (46), this property implies

$$
\widetilde{D}_{c}\left(\theta, c^{H}\right)>\Phi\left(\theta, c^{H}\right)>R_{c}\left(\theta, \widetilde{C}\left(\theta, c^{H}\right)\right) \frac{u^{\prime}\left(\widetilde{C}\left(\theta, c^{H}\right)\right) u^{\prime \prime}\left(c^{H}\right)}{u^{\prime \prime}\left(\widetilde{C}\left(\theta, c^{H}\right)\right) u^{\prime}\left(c^{H}\right)} \geq \underline{D_{c}}
$$

whenever $\widetilde{C}\left(\theta, c^{H}\right) \in[\underline{c}, \bar{c}]$.

We now prove the uniqueness of function $C(\theta)$ using Lemmata 2 and 3 . Suppose that there are two distinct functions $C_{1}(\theta)$ and $C_{2}(\theta)$, both of which satisfy (27) and (28). Let $c_{1}^{H} \equiv C_{1}\left(\theta^{H}\right)$ and $c_{2}^{H} \equiv C_{2}\left(\theta^{H}\right)$. Then $C_{1}(\theta)=\widetilde{C}\left(\theta, c_{1}^{H}\right)$ and $C_{2}(\theta)=\widetilde{C}\left(\theta, c_{2}^{H}\right)$ for all $\theta \in\left(\theta^{*}, \theta^{H}\right]$. Note that $c_{1}^{H} \neq c_{2}^{H}$ because we have assumed that $C_{1}(\theta)$ and $C_{2}(\theta)$ are distinct functions. Since $(28)$ is equivalent to (36), both functions satisfy

$$
\lim _{\theta \rightarrow \theta^{*}} \widetilde{D}\left(\theta, c_{1}^{H}\right)=\lim _{\theta \rightarrow \theta^{*}} \widetilde{D}\left(\theta, c_{2}^{H}\right)=0 .
$$

From Lemma 2, $\widetilde{C}\left(\theta, c_{1}^{H}\right), \widetilde{C}\left(\theta, c_{2}^{H}\right) \in[\underline{c}, \bar{c}]$ for all $\theta \in\left(\theta^{*}, \theta^{H}\right]$. Applying it to property $(a)$ of Lemma 3 implies $\widetilde{C}\left(\theta, c^{H}\right) \in[\underline{c}, \bar{c}]$ for all $c^{H} \in\left[c_{1}^{H}, c_{2}^{H}\right]$ and all $\theta \in\left(\theta^{*}, \theta^{H}\right]$. Thus, we can use property $(c)$ of Lemma 3 to obtain

$$
\lim _{\theta \rightarrow \theta^{*}}\left|\widetilde{D}\left(\theta, c_{1}^{H}\right)-\widetilde{D}\left(\theta, c_{2}^{H}\right)\right|>\left|c_{1}^{H}-c_{2}^{H}\right| \underline{D_{c}}>0
$$

which contradicts (47).

\section{The existence of $C(\theta)$}

We obtain another property with respect to $\widetilde{D}\left(\theta, c^{H}\right)$.

Lemma 4 Under Assumptions 2 and 3, (a) $\widetilde{D}(\theta, \underline{c})<0$ and (b) $\widetilde{D}(\theta, \bar{c})>0$ for all $\theta \in\left(\theta^{*}, \theta^{H}\right)$.

Proof: We first prove property (a). From (26) and (29),

$$
R\left(\theta^{H}, \underline{c}\right)=\rho \text { and } R(\theta, \underline{c})<\rho \text { for all } \theta \in\left(\theta^{*}, \theta^{H}\right) .
$$


Since (13) implies $h\left(\theta^{H}\right)=\theta^{H}$, substituting (35) and (49) into (37) yields

$$
\widetilde{D}\left(\theta^{H}, \underline{c}\right)=0 .
$$

Since (38) and (50) imply $\widetilde{C}_{\theta}\left(\theta^{H}, \underline{c}\right)=0$, and $R_{\theta}>0$ from (26), differentiating (37) with respect to $\theta$ when $\theta=\theta^{H}$ gives

$$
\widetilde{D}_{\theta}\left(\theta^{H}, \underline{c}\right)=R_{\theta}\left(\theta^{H}, \underline{c}\right)>0
$$

Equations (50) and (51) show that there is a small $\varepsilon(>0)$ such that $\widetilde{D}(\theta, \underline{c})<0$ for all $\theta \in$ $\left(\theta^{H}-\varepsilon, \theta^{H}\right)$.

We now extend the negativity of $\widetilde{D}(\theta, \underline{c})$ to the whole interval of $\left(\theta^{*}, \theta^{H}\right)$. To see this, suppose otherwise. Then, there must be some $\theta^{A} \in\left(\theta^{*}, \theta^{H}\right)$ such that $\widetilde{D}(\theta, \underline{c})<0$ for all $\theta \in\left(\theta^{A}, \theta^{H}\right)$ and that $\widetilde{D}\left(\theta^{A}, \underline{c}\right) \geq 0$. Since $\widetilde{D}<0 \Leftrightarrow \widetilde{C}_{\theta}>0$ from (38) and the negativity of $g(\theta)$ in (11), we obtain $\widetilde{C}\left(\theta^{A}, \underline{c}\right)<\widetilde{C}\left(h\left(\theta^{A}\right), \underline{c}\right)<\widetilde{C}\left(\theta^{H}, \underline{c}\right)=\underline{c}$. With Assumption 3 and (49), these inequalities yield $R\left(\theta^{A}, \widetilde{C}\left(\theta^{A}, \underline{c}\right)\right)<R\left(\theta^{A}, \underline{c}\right)<\rho$ and hence from $(37) \widetilde{D}\left(\theta^{A}, \underline{c}\right)<0$, which is a contradiction.

Next we prove property (b). From Assumptions 2 and 3,

$$
R(\theta, \bar{c})>\rho \text { for all } \theta \in\left(\theta^{*}, \theta^{H}\right]
$$

It implies $\widetilde{D}\left(\theta^{H}, \bar{c}\right)>0$ from (37) since $h\left(\theta^{H}\right)=\theta^{H}$ from (13). To prove that this inequality actually holds for whole $\left(\theta^{*}, \theta^{H}\right]$, suppose otherwise. Then, there should be some $\theta^{A} \in$ $\left(\theta^{*}, \theta^{H}\right)$ such that $\widetilde{D}(\theta, \bar{c})>0$ for all $\theta \in\left(\theta^{A}, \theta^{H}\right]$ and that $\widetilde{D}\left(\theta^{A}, \bar{c}\right) \leq 0$. From (31), we find $\widetilde{C}\left(\theta^{A}, \bar{c}\right)>\widetilde{C}\left(h\left(\theta^{A}\right), \bar{c}\right)>\widetilde{C}\left(\theta^{H}, \bar{c}\right)=\bar{c}$. With Assumption 3 and (52), these inequalities imply $R\left(\theta^{A}, \widetilde{C}\left(\theta^{A}, \bar{c}\right)\right)>R\left(\theta^{A}, \bar{c}\right)>\rho$ and therefore from $(37) \widetilde{D}\left(\theta^{A}, \bar{c}\right)>0$, which is again a contradiction.

Applying property $(b)$ of Lemma 3 and Lemma 4 to the intermediate value theorem assures that, for any given $\theta^{0} \in\left(\theta^{*}, \theta^{H}\right)$, there uniquely exists $c^{H} \in[\underline{c}, \bar{c}]$ that satisfies $\widetilde{D}\left(\theta^{0}, c^{H}\right)=0$. That is, there is a unique function, $c^{H}=\zeta\left(\theta^{0}\right)$, satisfying

$$
\widetilde{D}\left(\theta^{0}, \zeta\left(\theta^{0}\right)\right)=0 \text { for all } \theta^{0} \in\left(\theta^{*}, \theta^{H}\right) .
$$

From Lemmata 1 and 2, function $\widetilde{C}\left(\theta, \zeta\left(\theta^{0}\right)\right)$ is monotonic and bounded by $[\underline{c}, \bar{c}]$ within interval $\theta \in\left(\theta^{0}, \theta^{H}\right]$. By taking limit as $\theta^{0} \rightarrow \theta^{*}$, we conclude that $C(\theta)=\widetilde{C}\left(\theta, c^{H *}\right)$ is monotonic 
and bounded for all $\theta \in\left(\theta^{*}, \theta^{H}\right]$, where $c^{H *} \equiv \lim _{\theta^{0} \rightarrow \theta^{*}} \zeta\left(\theta^{0}\right) .{ }^{26}$ This implies $c_{t}$ should neither explode, implode nor oscillate. Thus $\dot{c}_{t} / c_{t} \rightarrow 0$ as $\theta_{t}^{e} \rightarrow \theta^{*}$, which gives the validity of boundary condition (28).

\section{Appendix B: Numerical Procedure for Finding $C(\cdot)$}

Our problem is generally called an IVP (initial value problem), which is usually solved by finite difference methods, such as the Runge-Kutta method and the Euler method. ${ }^{27}$ However, we cannot use them since the right-hand side of $(27)$ contains $C(h(\theta))$, which makes it impossible to calculate the gradient of $C(\theta)$ before $C(h(\theta))$ is determined. Since $h(\theta)$ is always larger than $\theta$, we cannot solve the differential equation forward from $\theta^{*}$, where the boundary condition is given, toward $\theta^{H}$. Instead, we can solve it backward from $\theta^{H}$ toward $\theta^{*}$, during which $C(h(\theta))$ is already known when we calculate the gradient of $C(\theta)$.

This strategy, however, involves another difficulty because the value of the function at the starting point, $c^{H} \equiv C\left(\theta^{H}\right)$, is not predetermined. Thus, we have to find an appropriate initial value $c^{H}$ such that boundary condition (28) is eventually met when (27) is solved from it. ${ }^{28}$ This method is in fact used when we prove proposition 1 in Appendix A, where we show that there is a unique $c^{H *} \in[\underline{c}, \bar{c}]$ that satisfies this property. In the numerical analysis we calculate $c^{H *}$ in the following way.

Step 1. Let $i=0, h_{0}=\bar{c}$ and $l_{0}=\underline{c}$.

Step 2. Let $c_{i}^{H}=\left(h_{i}+l_{i}\right) / 2$. Using the Euler method, solve differential equation (27) backward starting from boundary value $C\left(\theta^{H}\right)=c_{i}^{H}$.

Step 3. If $C(\theta)$ exceeds $\bar{c}$ during the calculation, or if $D(\theta)$ defined by (30) remains positive when $\theta$ approaches $\theta^{*}$, let $h_{i+1}=c_{i}^{H}$ and $l_{i+1}=l_{i}$. Conversely, if $C^{\prime}(\theta)$ becomes positive

\footnotetext{
${ }^{26}$ Note that $\zeta(\theta)$ is bounded by $\underline{c}$ and $\bar{c}$ from Lemma 2 . In addition, by totally differentiating (53) and utilizing Lemma 1 , we can prove that $\zeta(\theta)$ is continuous and monotonic for all $\theta \in\left(\theta^{*}, \theta^{H}\right]$. It means that $\zeta\left(\theta^{0}\right)$ does not oscillate as $\theta^{0} \rightarrow \theta^{*}$, hence the existence of $c^{H *} \equiv \lim _{\theta^{0} \rightarrow \theta^{*}} \zeta\left(\theta^{0}\right)$ is guaranteed.

${ }^{27}$ See, for example, Judd (1998).

${ }^{28}$ This method is usually called 'monkey hunting'.
} 
during the calculation or if $D(\theta)$ remains negative when $\theta$ approaches $\theta^{*}$, let $h_{i+1}=h_{i}$ and $l_{i+1}=c_{i}^{H}$. Otherwise, $c_{i}^{H}$ is the solution.

Step 4. Let $i=i+1$.

Step 5. Repeat steps $2-4$ until $h_{i}$ and $l_{i}$ get sufficiently close to each other. Then admit $c^{H}=$ $\left(h_{i}+l_{i}\right) / 2$ as the solution.

\section{References}

Acemoglu, D. and Scott, A. (1997) Asymmetric business cycles: Theory and time-series evidence, Journal of Monetary Economics, 40(3), 501-533.

Alpanda, S. (2019) Regime-switching productivity growth and bayesian learning in real business cycles, forthcoming in Macroeconomic Dynamics, DOI: 10.1017/S1365100519000257.

Andolfatto, D. and Gomme, P. (2003) Monetary policy regimes and beliefs, International Economic Review, 44(1), 1-30.

Atolia, M., Gibson, J. and Marquis, M. (2018) Asymmetry and the amplitude of business cycle fluctuations: A quantitative investigation of the role of financial frictions, Macroeconomic Dynamics, 22(2), 279-306.

Boldrin, M. and Levine, D.K. (2001) Growth cycles and market crashes, Journal of Economic Theory, 96, 13-39.

Boz, E., Daude, C. and Durdu, C.B. (2011) Emerging market business cycles: Learning about the trend, Journal of Monetary Economics, 58(6), 616-631.

Caballero, R.J. and Farhi, E. (2018) The safety trap, Review of Economic Studies, 85(1), 223274 .

Caplin, A. and Leahy, J. (1993) Sectoral shocks, learning, and aggregate fluctuations, Review of Economic Studies, 60, 777-794.

Cerra, V. and Saxena, S.C. (2008) Growth dynamics: The myth of economic recovery, American Economic Review, 98(1), 439-457. 
Chalkley, M. and Lee, I.H. (1998) Learning and asymmetric business cycles, Review of Economic Dynamics, 1, 623-645.

Dockner, E., Steffen, J., Van Long, N. and Sorger, G. (2000) Differential Games in Economics and Management Science.: Cambridge University Press.

Driffill, J. and Miller, M. (1993) Learning and inflation convergence in the ERM, Economic Journal, 103, 369-378.

Eggertsson, G.B., Mehrotra, N.R. and Robbins, J.A. (2019) A model of secular stagnation: Theory and quantitative evaluation, American Economic Journal: Macroeconomics, 11(1), 148.

Ferraro, D. (2018) The Asymmetric cyclical behavior of the U.S. labor market, Review of Economic Dynamics, 30, 145-162.

Hansen, G.D. and Prescott, E.C. (2005) Capacity constraints, asymmetries, and the business cycle, Review of Economic Dynamics, 8(4), 850-865.

Ikefuji, M. and Horii, R. (2012) Natural disasters in a two-sector model of endogenous growth, Journal of Public Economics, 96(9-10), 784-796.

Ikeda, D. and Kurozumi, T. (2019) Slow post-financial crisis recovery and monetary policy, American Economic Journal: Macroeconomics, 11(4), 82-112.

Illing, G., Ono, Y. and Schlegl, M. (2018) Credit booms, debt overhang and secular stagnation, European Economic Review, 108, 78-104.

Judd, K.L. (1998) Numerical Methods in Economics. Cambridge, MA: MIT Press.

Keynes, J.M. (1936) The General Theory of Employment, Interest, and Money. Cambridge: Macmillan and Cambridge University Press.

Lucas, R.E. (1978) Asset prices in an exchange economy, Econometrica, 46(6), 1429-1445.

Lorenzoni, G. (2009) A theory of demand shocks, American Economic Review, 99(5), 2050-2084.

McKay, A. and Reis, R. (2008) The brevity and violence of contractions and expansions, Journal of Monetary Economics, 55(4), 738-751. 
Neftci, S.N. (1984) Are economic time series asymmetric over the business cycle?, Journal of Political Economy, 92(2), 307-328.

Nieuwerburgh, S.V. and Veldkamp, L.L. (2006) Learning asymmetries in real business cycles, Journal of Monetary Economics, 53(4), 753-772.

Ono, Y. (1994) Money, Interest, and Stagnation: Oxford University Press.

Ono, Y. (2001) A reinterpretation of chapter 17 of Keynes's general theory: Effective demand shortage under dynamic optimization, International Economic Review, 42, 207-236.

Ono, Y. and Ishida, J. (2014) On persistent demand shortages: A behavioural approach, Japanese Economic Review, 65(1), 42-69.

Potter, S.M. (2000) A nonlinear model of business cycle, Studies in Nonlinear Dynamics and Econometrics, 4(2), 85-93.

Reinhart, C.M. and Reinhart, V.R. (2010) After the fall, NBER Working Papers 16334, National Bureau of Economic Research.

Schmitt-Grohé, S. and Uribe, M. (2017) Liquidity traps and jobless recoveries, American Economic Journal: Macroeconomics, 9(1), 165-204.

Sichel, D.E. (1993) Business cycle asymmetry: A deeper look, Economic Inquiry, 31(2), 224-236.

Sill, K. and Wrase, J. (1999) Exchange rates, monetary policy regimes, and beliefs, Federal Reserve Bank of Philadelphia Working Paper, 99-6.

Veldkamp, L.L. (2005) Slow boom, sudden crash, Journal of Economic Theory, 124(2), 230-257.

Zeira, J. (1994) Informational cycles, Review of Economic Studies, 61, 31-44.

Zeira, J. (1999) Informational overshooting, booms, and crashes, Journal of Monetary Economics, $43,237-257$. 